\title{
A dual role for hepatocyte-intrinsic canonical NF-кB signaling in virus control
}

\section{Graphical abstract}

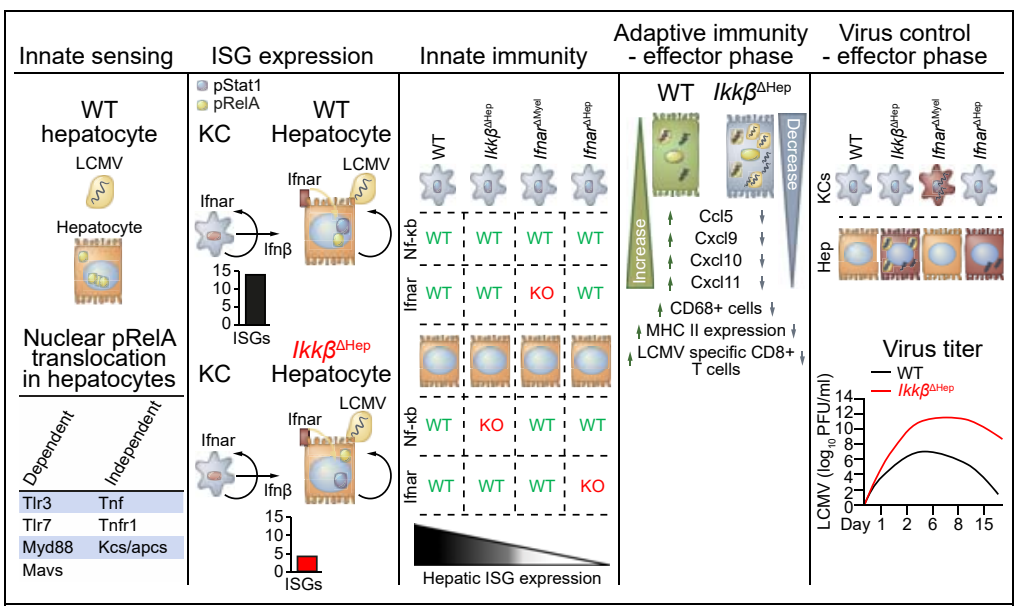

\section{Highlights}

- LCMV infection activates NF-KB signaling in hepatocytes.

- Macrophages, TNFR1 signaling do not induce LCMV-driven hepatocyte NF-kB-activation.

- $I k k \beta^{\Delta \mathrm{Hep}}$ mice display increased viral infection/replication and lower ISG induction.

- Ifnar ${ }^{\Delta \mathrm{Hep}}$ mice recapitulate aberrant virus replication as observed in $I k k \beta^{\Delta \mathrm{Hep}}$ mice.

- NF-KB signaling is required for efficient ISG induction in HBV-/HDV-infected HepaRG.

\section{Authors}

Sukumar Namineni, Tracy O'Connor, Suzanne Faure-Dupuy, ..., Ulrich Kalinke, Percy A. Knolle, Mathias Heikenwalder

\section{Correspondence}

m.heikenwaelder@dkfz-heidelberg.de (M. Heikenwalder).

\section{Lay summary}

Innate immune cells have been ascribed a primary role in controlling viral clearance upon hepatic infections. We identified a novel dual role for NF- $\mathrm{KB}$ signaling in infected hepatocytes which was crucial for maximizing interferon responses and initiating adaptive immunity, thereby efficiently controlling hepatic virus replication. 


\title{
A dual role for hepatocyte-intrinsic canonical NF-кB signaling in virus control
}

\author{
Sukumar Namineni ${ }^{1,2,3}$, Tracy O’Connor ${ }^{1,3, \dagger}$, Suzanne Faure-Dupuy ${ }^{1, \dagger}$, Pål Johansen ${ }^{4}$, \\ Tobias Riedl ${ }^{1}$, Kaijing Liu $^{5}$, Haifeng $\mathrm{Xu}^{6}$, Indrabahadur Singh ${ }^{7}$, Prashant Shinde ${ }^{8}$, Fanghui $\mathrm{Li}^{6}$, \\ Aleksandra Pandyra ${ }^{6}$, Piyush Sharma ${ }^{6,9}$, Marc Ringelhan ${ }^{1,2,10}$, Andreas Muschaweckh ${ }^{11}$, \\ Katharina Borst ${ }^{12}$, Patrick Blank ${ }^{12}$, Sandra Lampl ${ }^{3}$, Katharina Neuhaus ${ }^{1}$, David Durantel ${ }^{13}$, \\ Rayan Farhat ${ }^{13}$, Achim Weber ${ }^{14}$, Daniela Lenggenhager ${ }^{14}$, Thomas M. Kündig ${ }^{4}$, \\ Peter Staeheli ${ }^{15}$, Ulrike Protzer ${ }^{1,2}$, Dirk Wohlleber ${ }^{3}$, Bernhard Holzmann ${ }^{16}$, Marco Binder ${ }^{17}$, \\ Kai Breuhahn ${ }^{5}$, Lisa Mareike Assmus ${ }^{18}$, Jacob Nattermann ${ }^{19}$, Zeinab Abdullah ${ }^{18}$, \\ Maude Rolland ${ }^{20}$, Emmanuel Dejardin ${ }^{20}$, Philipp A. Lang ${ }^{8}$, Karl S. Lang ${ }^{6}$, Michael Karin ${ }^{21}$, \\ Julie Lucifora $^{13}$, Ulrich Kalinke ${ }^{12}$, Percy A. Knolle ${ }^{3}$, Mathias Heikenwalder ${ }^{1,2,3, *}$
}

\begin{abstract}
${ }^{1}$ Division of Chronic Inflammation and Cancer, German Cancer Research Center (DKFZ), Heidelberg, Germany; ${ }^{2}$ Institute of Virology, Technical University of Munich and Helmholtz Zentrum München, Schneckenburgerstrasse 8, 81675 Munich, Germany; ${ }^{3}$ Institute of Molecular Immunology and Experimental Oncology, Technical University of Munich, Ismaningerstraße 22, 81675 Munich, Germany; ${ }^{4}$ Department of Dermatology, University Hospital Zurich and University of Zurich, Gloriastrasse 31, 8091 Zurich, Switzerland; ${ }^{5}$ Institute of Pathology, University Hospital Heidelberg, Heidelberg, Germany; ${ }^{6}$ Institute of Immunology, Medical Faculty, University of Duisburg-Essen, Hufelandstr. 55, Essen 45147, Germany; ${ }^{7}$ Emmy Noether Research Group Epigenetic Machineries and Cancer, Division of Chronic Inflammation and Cancer, German Cancer Research Center (DKFZ), Heidelberg, Germany; ${ }^{8}$ Department of Molecular Medicine II, Medical Faculty, Heinrich Heine University, Universitätstr.1, 40225 Düsseldorf, Germany; ${ }^{9}$ Department of Immunology, St. Jude Children's Research Hospital, Memphis, TN, USA, 38105; ${ }^{10}$ Department of Internal Medicine II, University Hospital rechts der Isar, Technical University of Munich, Ismaninger Str. 22, 81675 Munich, Germany; ${ }^{11}$ Klinikum rechts der Isar, Department of Neurology, Technical University of Munich, Ismaninger Str. 22,81675 Munich, Germany; ${ }^{12}$ Institute for Experimental Infection Research, TWINCORE, Centre for Experimental and Clinical Infection Research, a joint venture between the Hanover Medical School and the Helmholtz Centre for Infection Research, Brunswick, Germany; ${ }^{13}$ INSERM, U1052, Cancer Research Center of Lyon (CRCL), Université de Lyon (UCBL1), CNRS UMR 5286, Centre Léon Bérard, Lyon, France; ${ }^{14}$ Department of Pathology and Molecular Pathology, University Hospital of Zurich, 8091 Zurich, Switzerland; ${ }^{15}$ Institute of Virology, University of Freiburg, Freiburg, Germany; ${ }^{16}$ Department of Surgery, Klinikum rechts der Isar, Technische Universität München, Munich, Germany; ${ }^{17}$ Research Group "Dynamics of Early Viral Infection and the Innate Antiviral Response", Division Virus-Associated Carcinogenesis (F170), German Cancer Research Center (DKFZ), 69120 Heidelberg, Germany; ${ }^{18}$ Institute of Experimental Immunology, Bonn, Germany; ${ }^{19}$ Department of Internal Medicine, University of Bonn, Bonn, Germany; ${ }^{20}$ Laboratory of Molecular Immunology and Signal Transduction, GIGA-Institute, University of Liège, 4000 Liège, Belgium; ${ }^{21}$ Laboratory of Gene Regulation and Signal Transduction, Department of Pharmacology, School of Medicine, University of California San Diego (UCSD), 9500 Gilman Drive, La Jolla, California 92093, USA
\end{abstract}

Background \& Aims: Hepatic innate immune control of viral infections has largely been attributed to Kupffer cells, the liverresident macrophages. However, hepatocytes, the parenchymal cells of the liver, also possess potent immunological functions in addition to their known metabolic functions. Owing to their abundance in the liver and known immunological functions, we aimed to investigate the direct antiviral mechanisms employed by hepatocytes.

Methods: Using lymphocytic choriomeningitis virus (LCMV) as a model of liver infection, we first assessed the role of myeloid cells by depletion prior to infection. We investigated the role of

\footnotetext{
Keywords: Hepatocytes; Innate immune responses; NF-kB signaling; PRRs; Interferon-stimulated genes; Cytotoxic T cells.

Received 6 May 2019; received in revised form 2 December 2019; accepted 11 December 2019; available online 15 January 2020

* Corresponding author. Address: Division Chronic Inflammation and Cancer (F180), German Cancer Research Center (DKFZ), Im Neuenheimer Feld 242, 69120 Heidelberg, Germany; Tel.: +49 6221 42-3891, fax: +49 6221 42-3899.

E-mail address: m.heikenwaelder@dkfz-heidelberg.de (M. Heikenwalder).

Contributed equally

https://doi.org/10.1016/j.jhep.2019.12.019
}

hepatocyte-intrinsic innate immune signaling by infecting mice lacking canonical NF- $\kappa \mathrm{B}$ signaling $\left(I k k \beta^{\Delta \mathrm{Hep}}\right)$ specifically in hepatocytes. In addition, mice lacking hepatocyte-specific interferon- $\alpha / \beta$ signaling-(Ifnar $\left.{ }^{\Delta \mathrm{Hep}}\right)$, or interferon- $\alpha / \beta$ signaling in myeloid cells-(Ifnar $\left.{ }^{\Delta \text { Myel }}\right)$ were infected.

Results: Here, we demonstrate that LCMV activates NF-кB signaling in hepatocytes. LCMV-triggered NF- $\mathrm{KB}$ activation in hepatocytes did not depend on Kupffer cells or TNFR1 signaling but rather on Toll-like receptor signaling. LCMV-infected $I k k \beta^{\Delta \mathrm{Hep}}$ livers displayed strongly elevated viral titers due to LCMV accumulation within hepatocytes, reduced interferonstimulated gene (ISG) expression, delayed intrahepatic immune cell influx and delayed intrahepatic LCMV-specific CD8 ${ }^{+}$ $\mathrm{T}$ cell responses. Notably, viral clearance and ISG expression were also reduced in LCMV-infected primary hepatocytes lacking IKK $\beta$, demonstrating a hepatocyte-intrinsic effect. Similar to livers of $I k k \beta^{\Delta \mathrm{Hep}}$ mice, enhanced hepatocytic LCMV accumulation was observed in livers of Ifnar ${ }^{\Delta \mathrm{Hep}}$ mice, whereas Ifnar $^{\Delta \mathrm{Myel}}$ mice were able to control LCMV infection. Hepatocytic NF- $\kappa \mathrm{B}$ signaling was also required for efficient ISG 


\section{JOURNAL OF HEPATOLOGY}

induction in HDV-infected dHepaRG cells and interferon- $\alpha / \beta$ mediated inhibition of HBV replication in vitro.

Conclusions: Together, these data show that hepatocyteintrinsic NF- $\mathrm{\kappa B}$ is a vital amplifier of interferon- $\alpha / \beta$ signaling, which is pivotal for strong early ISG responses, immune cell infiltration and hepatic viral clearance.

Lay summary: Innate immune cells have been ascribed a primary role in controlling viral clearance upon hepatic infections. We identified a novel dual role for NF- $\mathrm{KB}$ signaling in infected hepatocytes which was crucial for maximizing interferon responses and initiating adaptive immunity, thereby efficiently controlling hepatic virus replication.

(c) 2020 Published by Elsevier B.V. on behalf of European Association for the Study of the Liver. This is an open access article under the CC BY-NC-ND license (http://creativecommons.org/licenses/by-ncnd/4.0/).

\section{Introduction}

The liver is constantly exposed to pathogens coming from the gut via the hepatic portal vein. ${ }^{1}$ Owing to this unique anatomical position, the liver not only serves as a metabolic organ but also plays a central role in supporting innate and local adaptive immunity. ${ }^{2}$ While maintaining immune tolerance, the liver continuously removes a large and diverse spectrum of pathogens from the circulation, assuring organ protection. ${ }^{3}$ The liver has the largest population of resident macrophages in the whole body. ${ }^{3}$ Consequently, a sub-lethal bacterial inoculum in mice depleted of liver-resident macrophages (Kupffer cells [KCs]) leads to increased bacterial load, dissemination and death, ${ }^{4,5}$ suggesting that the liver plays a non-redundant role in conferring immunity to infections.

Hepatocytes are parenchymal cells of the liver encompassing $\sim 80 \%$ of the entire liver cell mass. In addition to being centrally involved in metabolic functions, plasma protein expression and detoxification, hepatocytes are known to possess potent immunological functions. ${ }^{6,7}$ Several pathogen recognition receptors (PRRs) are strongly expressed by hepatocytes. ${ }^{8}$ Upon encountering pathogen-associated molecular patterns (PAMPs), hepatocytes readily secrete inflammatory cytokines, which help control the spread and growth of pathogens. ${ }^{9}$ Owing to their abundance in the liver and known immune functions, we aimed to investigate the direct/indirect antiviral mechanisms employed by hepatocytes.

Efficient clearance of a viral infection requires early detection of viral DNA or RNA by PRRs and induction of interferon responses, which serve as the first line of defense. Interferons act by binding to type I interferon receptors (IFNARs) on the cell surface, initiating a signaling cascade via the JAK-STAT pathway that leads to the upregulation of interferon-stimulated genes (ISGs). Induction of ISG responses creates an effective cellintrinsic antiviral state, which restricts the replication of most viruses at an early stage. ${ }^{10}$

Non-cytopathic lymphocytic choriomeningitis virus (LCMV$\mathrm{WE}$ ) is a negative-sense single-stranded RNA virus belonging to the Arenaviridae family. ${ }^{11,12}$ The replication intermediates of this virus involve formation of double stranded RNA and 5'-PPP structures, which are recognized by RIG-I and MDA5 activating IRF3 and NF-kB-mediated interferon responses. ${ }^{13,14}$ While the downstream signaling from the receptors of these stimuli might vary in most cases, they all converge on the activation of the IKK
(IкB kinase) complex. The IKK complex consists of 2 catalytic kinase subunits, IKK $\alpha$ and IKK $\beta$ with intrinsic kinase activities and a regulatory subunit, IKK $\gamma$, also known as NF- $\mathrm{KB}$ essential modulator (NEMO) with helix-loop helix and leucine-zipper motifs that mediate protein-protein interactions. ${ }^{15,16}$ In the inactive state p50:p65 dimers are held in the cytoplasm in association with the inhibitors of kappaB (IKB) proteins, which mask the nuclear localization signal. The activated IKK complex phosphorylates IкB proteins at amino terminal serine residues and marks them for ubiquitin-mediated proteasomal degradation, upon which NF- $\mathrm{KB}$ dimers translocate to the nucleus to bind DNA and enable gene transcription.

NF- $\kappa \mathrm{B}$ is activated by multiple viruses such as HIV, HCV, Rio Bravo virus and influenza to enhance viral replication or escape virus-induced apoptosis. ${ }^{17}$ Some viruses, such as Vaccinia virus, encode proteins with ankyrin repeats mimicking I $\kappa B$ family proteins, thereby inhibiting NF- $\mathrm{kB}$ signaling and subsequent immune responses. ${ }^{18}$ Furthermore, IKK $\beta$ is essential for the induction of type I interferon (IFN) and other inflammatory cytokines in response to a viral infection. ${ }^{19}$

To determine the relative contribution of hepatocytes to viral clearance in the liver, we used a mouse model in which the essential upstream kinase in canonical NF- $\mathrm{KB}$ signaling, IKK $\beta$, was selectively deleted in hepatocytes by Cre recombinasemediated excision under the control of the albumin promoter $I k k \beta^{\Delta \text { Hep }}$ mice. ${ }^{20-23}$ These Ikk $\beta^{\Delta \text { Hep }}$ mice were infected systemically with LCMV-WE strain. LCMV-WE leads to an acute infection that is usually cleared within $2-3$ weeks by virus-specific $C D 8^{+}$ $\mathrm{T}$ cells. Intravenous infection in mice leads to infection of multiple visceral organs such as the lung, kidney, spleen, and liver. ${ }^{24,25}$ Following a systemic infection with LCMV in I $k k \beta^{\Delta \text { Hep }}$ mice, we analyzed the dynamics of viral replication and clearance with a focus on the relative contribution of hepatocytes compared to Ifnar $^{\Delta \mathrm{Hep}}$, Ifnar ${ }^{\Delta \mathrm{Myel}}$, and wild-type (WT) livers. Our findings were corroborated in differentiated HepaRG cells lacking IKK $\beta$ either treated with IFN- $\alpha / \mathrm{TNF} \alpha$ or infected with HDV. Our results highlight a central role of hepatocyte-intrinsic NF- $\mathrm{KB}$ signaling in supporting innate and adaptive immune responses to systemic viral infections.

\section{Materials and methods}

\section{Animals and infections}

Alb-Cre transgenic mice expressing Cre recombinase from the hepatocyte-specific albumin promoter were crossed with $I k k \beta^{\mathrm{f} / \mathrm{fl}}$ mice and Ifnar ${ }^{\text {fl/fl }}$ mice to generate Ikk $\beta^{\Delta \mathrm{Hep}}$ mice and Ifnar ${ }^{\Delta \mathrm{Hep}}$ mice. ${ }^{20-22}$ LysM-Cre mice expressing Cre in myeloid cells due to a targeted insertion of the Cre cDNA into their endogenous $\mathrm{M}$ lysozyme locus were crossed with Ifnar ${ }^{\mathrm{f} / \mathrm{fl}}$ mice to generate Ifnar ${ }^{\Delta \text { Myel }}$ mice. ${ }^{26}$ To control the effects of Cre-induced cytotoxicity, histology was performed on livers obtained from C57BL/6 (WT), Alb-Cre, and Ikk $\beta^{\Delta \text { hep }}$ mice. No phenotypic differences were observed between WT and Alb-Cre mice. A total of 237 mice, of both male and female gender, aged between 4 to 5 months were used in the experiments. Each experiment has been performed with 3 to 6 mice. Mice used for experiments were maintained in single ventilated cages and under specific pathogen-free conditions. All mice used were of a C57BL/6/J genetic background. LCMV-WE was originally obtained from Rolf Zinkernagel (University Hospital Zurich (USZ), Switzerland) and propagated by infection of $L 929$ fibroblast cells. Infection experiments were performed in Zurich under the licenses 
ZH 200/2006 and ZH 69/2012 as approved from the cantonal veterinary office of Zurich. Infection doses were given as indicated in each experiment, intravenously. At least 3-6 mice were used in each experimental group.

\section{LCMV nuclear protein immunofluorescence}

Five micrometer liver cryo-sections, taken from LCMV-infected mice, were fixed in ice-cold $100 \%$ acetone for $10 \mathrm{~min}$ on glass coverslips (ThermoFisher). Sections were then blocked for 15 min in $2 \%$ fetal calf serum (FCS; Hyclone) in PBS. Sections were then incubated overnight at $4{ }^{\circ} \mathrm{C}$ in anti-LCMV nuclear protein (NP) supernatant (clone VL4) ${ }^{24}$ diluted $1: 4$ in $2 \%$ FCS in PBS. Sections were washed in PBS and incubated for $1 \mathrm{~h}$ in $2 \mu \mathrm{g} / \mathrm{ml}$ AlexaFluor 488-conjugated goat anti-rat secondary antibody (Invitrogen) containing 1:10,000 DAPI in 2\% FCS in PBS. Sections were then washed in PBS and mounted with fluorescent mounting medium (Dako), cover-slipped, and imaged using an Olympus BX53F fluorescent microscope or with a confocal Zeiss LSM 710 ConfoCor 3.

\section{RelA immunofluorescence}

Five micrometer liver cryo-sections, taken from LCMV-infected mice, were fixed in $4 \%$ formalin for $10 \mathrm{~min}$, washed in PBS for $2 \mathrm{~min}$, and then washed for $10 \mathrm{~min}$ in PBS with $0.1 \%$ Tween 20 (PBST). Sections were then blocked for $1 \mathrm{~h}$ in 5\% FCS and $0.25 \%$ Triton X-100 in PBS. Sections were then incubated at $4^{\circ} \mathrm{C}$ overnight in anti-RelA (NeoMarkers \# RB-1638-P0) diluted 1:100 in $1 \%$ bovine serum albumin (BSA), $0.25 \%$ Triton-X 100 in PBS. Sections were then washed in PBS for 2 min, followed by PBST for $2 \mathrm{~min}$, and incubated for $1 \mathrm{~h}$ in $4 \mu \mathrm{g} / \mathrm{ml}$ AlexaFluor 488 conjugated goat anti-rabbit secondary antibody containing $1: 10,000$ DAPI in $1 \%$ BSA and $0.25 \%$ Triton-X 100 in PBS. Sections were then washed in PBS followed by $1 \times$ PBST, mounted with fluorescent mounting medium, cover-slipped, and imaged using an Olympus BX53F fluorescent microscope.

\section{CXCL10 and TNF $\alpha$ RNA in situ hybridization}

RNA in situ hybridization (ISH) was performed on the liver tissues by following manufacturer instructions for RNAscope 2.0 FFPE Assay kit -BROWN, purchased from Advanced Cell Diagnostics. Briefly, $2 \mu \mathrm{m}$ paraffin sections mounted on glass slides were boiled at $100^{\circ} \mathrm{C}$ in EZprep buffer for 20 min followed by a protease treatment at $37^{\circ} \mathrm{C}$ for $30 \mathrm{~min}$. Probes specific to mouse CXCL10 or TNFa (Advanced Cell Diagnostics) were hybridized at $48^{\circ} \mathrm{C}$ for $2 \mathrm{~h}$ using HybEZ Hybridization oven (Advanced Cell Diagnostics) followed by a subsequent series of washing and signal amplification steps. Mouse specific probe for ubiquitin $\mathrm{C}$, a common housekeeping gene is used as a positive control along with a probe for bacterial gene dapB which served as a negative control. In the end, hybridization signals were detected by DAB staining followed by counterstaining with hematoxylin. Stained tissues were digitally scanned using Leica SCN400 scanner (Leica) and hybridization signals were analyzed at 40x magnification using DIH software (Leica).

\section{Primary hepatocyte isolation}

Mice were anesthetized with $120 \mu$ l ketamine and xylazine (ketamine 5\%, xylazine $2 \mathrm{mg} / \mathrm{ml}$ ). Livers were perfused with buffer A (10 mM EGTA $1.5 \mathrm{ml}+48.5 \mathrm{ml}$ Hank's balanced salt solution) through the portal vein for $5 \mathrm{~min}$. The vena cava was cut as soon as the perfusion was started, and the perfusion was switched to buffer B (HBSS with $10 \mathrm{mM}$ Calcium \& Collagenase $A+D$, freshly prepared) and carried out until the liver turned pale (5-8 min). The liver was later removed and placed in a $100 \mu \mathrm{m}$ cell strainer in a petri dish containing William's E medium. The resulting solution was passed through a $100 \mu \mathrm{m}$ (BD Biosciences) cell strainer and collected into a $50 \mathrm{ml}$ falcon filled with $40 \mathrm{ml}$ of buffer C (William's E Medium). The cell suspension was centrifuged at $50 \mathrm{~g}(450 \mathrm{rpm})$ for $2 \mathrm{~min}$. The resulting pellet was washed again twice in $40 \mathrm{ml}$ of buffer $\mathrm{C}$ followed by centrifugation after discarding the supernatant. After the final wash step, the pellet was re-suspended in $10 \mathrm{ml}$ of buffer $C$ and the viability of isolated cells was measured using trypan blue at a $1: 10$ dilution. A viability rate above $80 \%$ was considered appropriate for experimental usage. A total of $0.75 \times 10^{6}$ cells were plated onto 6-well plates in required quantities and used for the experiments.

\section{Generation of differentiated HepaRG ${ }^{\Delta I K K \beta}$ KO cell line}

To knock out $I k k \beta$, single guide ( $\operatorname{sg}$ )RNAs were chosen based on high scoring and no high scoring off-targets using CHOPCHOP v2 web tool. ${ }^{27}$ These sgRNAs were inserted into pUSEPR (generous gift from Dr. Tscharaganeh, unpublished) based on methods as described elsewhere. ${ }^{28}$ Briefly, a sgRNA scaffold fragment was attached to the 5' end of a U6 promoter by using overlap extention PCR. In a subsequent PCR reaction, 20 nucleotide sgRNAs were added to the 5' end of the sgRNA scaffold and the 3' end of the U6 promoter. BsmBI sites added upstream of the 5'sgRNA and downstream of the 3'-sgRNA were used to seamlessly clone the 5'-sgRNA-sgRNA scaffold-U6 Promoter-sgRNA-3' fragment into the vector backbone via golden gate assembly (10 U BsmBI; 400 U T4 DNA Ligase; 1 mM ATP; 1x NEBuffer 3.1; 0.03 pmol vector backbone; 0.3 pmol insert). Preparation of lentiviral particles and transduction of HepaRGs were performed based on protocols from addgene. Differentiated WT HepaRG or differentiated HepaRG-iCas9-pUSEPR (HepaRG ${ }^{\Delta l k k \beta}$ ) cells were treated with $50 \mathrm{ng} / \mathrm{ml}$ of IFN- $\alpha$ and $10 \mathrm{ng} / \mathrm{ml}$ of TNF $\alpha$ for $12 \mathrm{~h}$.

\section{Patient populations}

This study involved a total number of 79 females at the age of $24.7 \pm 4$ from the East German anti-D cohort: women infected between 1978 and 1979 by administration of prophylactic anti-D immunoglobulin contaminated with HCV genotype 1b from a single source. All individuals were from a limited geographic area in Germany with similar socioeconomic living conditions. None of these individuals had any other known risk factors for viral hepatitis or chronic liver disease, and they were all HIV-negative at the time point of sampling. ${ }^{29}$ This studied comprised 57 with chronic (HCV RNA positive after repeated examination) and 22 with spontaneously resolved (HCV RNA negative after repeated examination) HCV infection. Diagnosis of chronic or resolved $\mathrm{HCV}$ infection was determined according to established guidelines based on standard serological and clinical criteria. The study has been approved by the research and ethic committee at Bonn University and informed consent was obtained from all participants prior to inclusion in the study.

\section{Statistical analysis}

A statistical analysis of the data was performed using Prism software (Graphpad Prism version 5.0a). The standard error of the mean was calculated from the average of at least 3 independent samples in a given treatment condition. To evaluate 


\section{JOURNAL OF HEPATOLOGY}

statistical significance, results were subjected to Student's $t$ test (unpaired, two-tailed test) and a $p$ value of less than 0.05 were considered significant; ${ }^{*} p<0.05,{ }^{* *} p<0.01,{ }^{* * *} p<0.001$.

\section{Results}

LCMV-induced hepatocytic NF-kB signaling is required for hepatic virus control, independent of $\mathrm{KC}$-derived factors

Given the central role of NF- $\kappa B$ signaling in PRR-mediated viral sensing and activation of innate immunity, we tested whether LCMV infection would activate NF- $\mathrm{KB}$ signaling in liver parenchymal cells. To this end, WT mice were intravenously infected with $2 \times 10^{6}$ plaque-forming units (PFUs) of LCMV, and $12 \mathrm{~h}$ postinfection (p.i.), nuclear RelA translocation was analyzed in livers by immunohistochemistry. Notably, nuclear RelA translocation was found in hepatocytes and to a lesser degree in KCs of infected livers (Fig. 1A). As TNF $\alpha$ is a major driver of nuclear RelA translocation, we first investigated hepatic TNF $\alpha$ expression. LCMV infection elevated Tnf $\alpha$ mRNA in liver and TNF $\alpha$ protein in serum (Figs. S1A, upper and lower left panels), which could be mainly localized to non-parenchymal cells as analyzed by RNA in situ hybridization (Fig. S1A, right panel). Further, sequential staining of $T n f \alpha$ by RNA in situ hybridization with F4/80 demonstrated that the majority of $\operatorname{Tnf} \alpha$ mRNA-expressing cells are $\mathrm{F} 4 / 80^{+} \mathrm{KCs}$ (Fig. S1B). To determine whether KCs, the major TNF $\alpha$-producing cell type in the liver or other phagocytosing antigen-presenting cells (APCs) were required for LCMV-induced nuclear RelA translocation in hepatocytes, mice were treated with clodronate liposomes prior to infection, which efficiently depleted phagocytic F4/80 ${ }^{+}$cells in the liver (Fig. S1C). Despite the efficient depletion of KCs, efficacy of nuclear RelA translocation in hepatocytes remained unchanged at $24 \mathrm{~h}$ p.i. (Fig. S1C). Moreover, Tnfr $1^{-/-}$mice displayed unchanged nuclear RelA translocation upon LCMV infection compared to WT livers (Figs. S1 D and S1E). Consecutive staining of RelA/HNF4 $\alpha$ or RelA/ F4/80 in livers of $\mathrm{TnFr}^{-/-}$mice indicated that RelA translocation can be found mainly in hepatocytes (Fig. S1F). This suggests that LCMV-induced RelA translocation and subsequent NF- $\kappa B$ signaling in hepatocytes is not mediated by phagocytic immune cell populations such as KCs, or cytokines produced by the latter, and could be due to the sensing of LCMV through PRRs, such as Toll-like receptor (TLR)3 within hepatocytes (Figs. S1D and S1E).

To determine which PRRs were required for LCMV-mediated RelA translocation in hepatocytes, we infected mice lacking several key viral sensing molecules with LCMV (Figs. S1D and E). Hepatocytic RelA translocation was significantly reduced in livers of $T l r 3^{-/-}$or $T l r 7^{-/-}$mice after LCMV infection, indicating that intracellular RNA sensing by these PRRs is involved. Loss of the adapter protein for RIG-I and MDA5 signaling, MAVS, and a key adapter protein in TLR signaling - MyD88 - also resulted in a significant reduction in nuclear RelA translocation in hepatocytes post-LCMV infection. In contrast, nuclear RelA levels remained unchanged in hepatocytes devoid of STING (Sting ${ }^{-/}$), an intracellular DNA sensor, compared to WT (Figs. S1D and E).

To elucidate the role of hepatocyte-specific NF- $\kappa B$ signaling in the context of virus infections, we next analyzed mice with a selective deletion of $I k k \beta$ in liver parenchymal cells $\left(I k k \beta^{\Delta \mathrm{Hep}}\right.$ mice). Specific deletion of $I k k \beta$ in liver parenchymal cells was confirmed via mRNA expression analysis of whole livers, spleens for control, and isolated hepatocytes from $I k k \beta^{\Delta \mathrm{Hep}}$ and WT mice (Fig. S1G). WT and $I k k \beta^{\Delta \mathrm{Hep}}$ mice were infected intravenously with LCMV and stained for RelA. Nuclear RelA translocation was observed in hepatocytes from LCMV-infected WT mice with a peak at $12 \mathrm{~h}$ p.i., whereas $I k k \beta^{\Delta \mathrm{Hep}}$ mice infected with the same dose of LCMV-WE lacked significant RelA translocation in the nuclei of hepatocytes (Fig. 1B). Of note, activation of the JNK pathway, analyzed by c-JUN phosphorylation and subsequent nuclear translocation, was lower in $I k k \beta^{\Delta \mathrm{Hep}}$ mice compared to WT (Fig. S1H).

To evaluate the functional consequence of hepatocyte-specific inhibition of canonical NF- $\kappa B$ signaling, we compared virus titers from the livers of $I k k \beta^{\Delta H e p}$ and WT mice infected with different doses of LCMV. Strikingly, an approximately 100-fold increase in virus titers at the peak of infection was found in livers of $I k k \beta^{\Delta \mathrm{Hep}}$ mice compared to WT mice (Fig. 1C). Similar virus titers in spleens of $I k k \beta^{\Delta \mathrm{Hep}}$ as in WT mice suggest that peripheral viral control is not dramatically affected (Fig. S1I). Furthermore, the abundance of $\mathrm{CD}_{169}{ }^{+}$splenic macrophages was analyzed in WT and $I k k \beta^{\Delta \mathrm{Hep}}$ mice by immunofluorescence and not found to be significantly different (Fig. S1J). In addition, flow cytometry of splenic and hepatic immune cells did not reveal differences in dendritic cell maturation between the WT and $I k k \beta^{\Delta \mathrm{Hep}}$ mice at day 3 p.i. (Fig. S1K).

\section{LCMV predominantly accumulates in hepatocytes of Ikk $\beta^{\Delta \mathrm{Hep}}$ livers}

To identify the cell types in which LCMV is accumulating and actively replicating over time, we analyzed the cellular localization of LCMV in frozen liver sections of WT and $I k k \beta^{\Delta \mathrm{Hep}}$ mice p.i. with $2 \times 10^{6}$ PFUs of LCMV at different time points by staining for LCMV-NP. ${ }^{24,30}$ While LCMV-WE was localized to cells exhibiting Kupffer cell-like morphology as early as day 2 p.i., LCMV-WE was also sporadically detected in hepatocytes by days 6 and 8 p.i. in WT livers, indicating that LCMV-WE also replicates at very low levels in hepatocytes (Fig. 1D) contrary to earlier findings illustrating KCs as the only cell type in the liver responsible for the intake and reduction of viral titers. ${ }^{24}$ Strikingly, hepatocytes from $I k k \beta^{\Delta \mathrm{Hep}}$ mice displayed large clusters filled with LCMV-NP, particularly at days 6 and 8 p.i., due to defective NF- $\kappa B$ signaling in hepatocytes (Fig. 1D). An approximate 10-fold increase in LCMV-WE ${ }^{+}$hepatic area was found in $I k k \beta^{\Delta \mathrm{Hep}}$ compared to WT livers (Fig. 1D). Co-stains of LCMV-NP with $\mathrm{F} 4 / 80^{+}$(KCs) or HNF4 $\alpha^{+}$(hepatocytes) demonstrated that at day 2 p.i., LCMV-NP localized exclusively in macrophages, whereas at days 6 and 8 p.i., $\mathrm{LCMV}^{+}$cells in $I k k \beta^{\Delta \mathrm{Hep}}$ livers were mainly hepatocytes, as identified by positive staining for HNF4 $\alpha$ (Figs. 1E and Fig. S1L). Of note, whereas the initial number of LCMVinfected $\mathrm{F} 4 / 80^{+}$cells was similar between both genotypes at day 2 p.i., a significantly higher number of LCMV-infected $\mathrm{F} 4 / 80^{+}$cells was observed in $I k k \beta^{\Delta \mathrm{Hep}}$ than in WT livers at day 8 p.i. (Fig. 1E).

\section{Loss of NF-кB signaling in hepatocytes leads to impaired IFN responses}

Considering the critical role of IKK $\beta$ in the induction of IFN responses, ${ }^{19,31,32}$ we investigated whether $I k k \beta^{\Delta \text { Hep }}$ livers were defective in the early induction of IFN responses following LCMV infection. To this end, WT and $I k k \beta^{\Delta \mathrm{Hep}}$ mice were infected with LCMV, and ISG expression was measured over time by qRT-PCR. A reduction in ISG expression was observed in livers of $I k k \beta^{\Delta \mathrm{Hep}}$ compared to WT mice, especially at $18 \mathrm{~h}$ and $24 \mathrm{~h}$ p.i. (Fig. 2A). Among the differentially expressed ISGs, $M x 1$, Ifit1, Ifit2, Oas1, Oas3 were significantly reduced in $I k k \beta^{\Delta \mathrm{Hep}}$ mice (Figs. $2 \mathrm{~A}$ and S2A). 

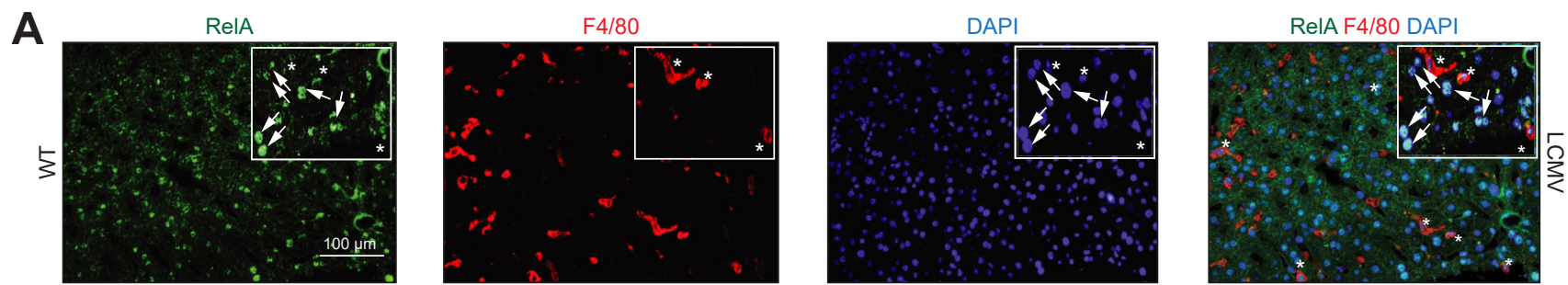

B

RelA-DAP|

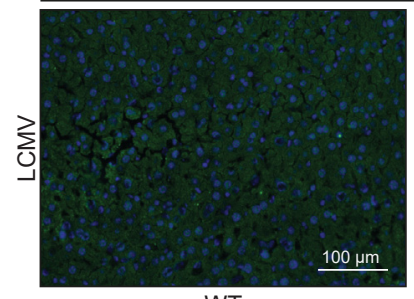

WT
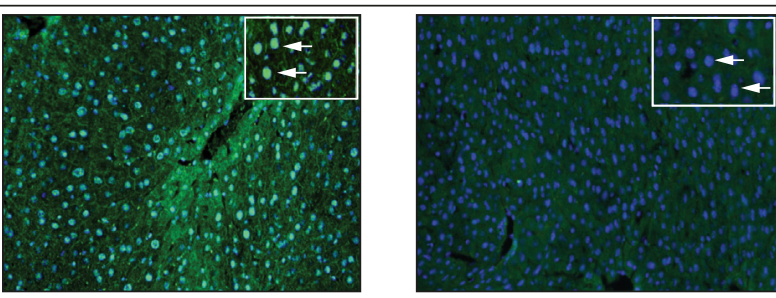

WT

$I k k \beta^{\text {АHep }}$

C

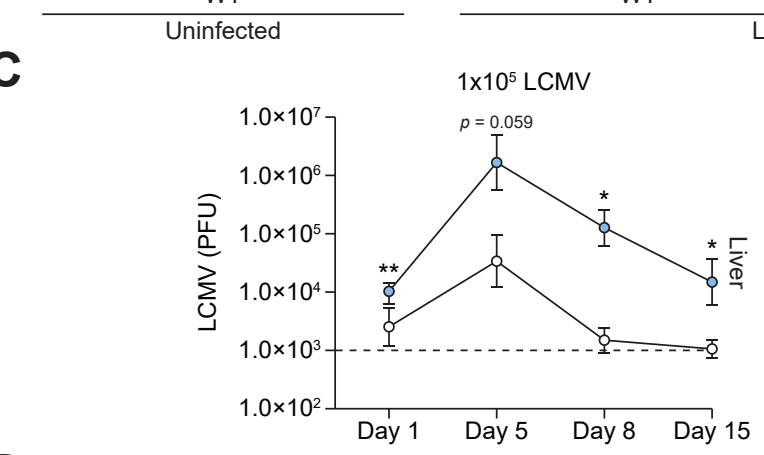

LCMV 2×10 $\mathrm{PFU}$

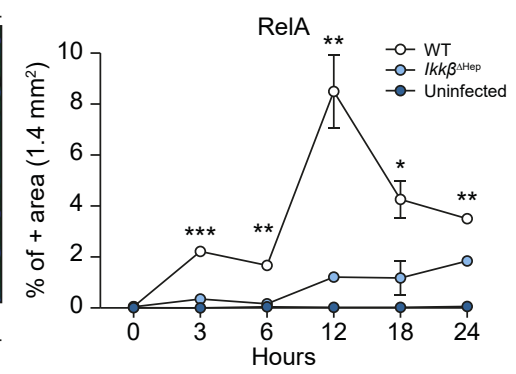

D

Day 0
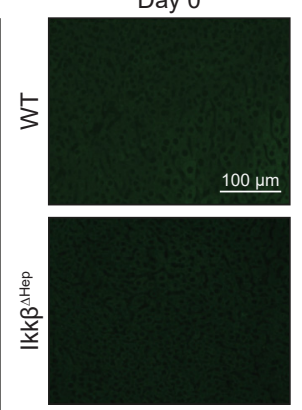

$\sum_{0}^{\substack{1 \\ \hline}}$
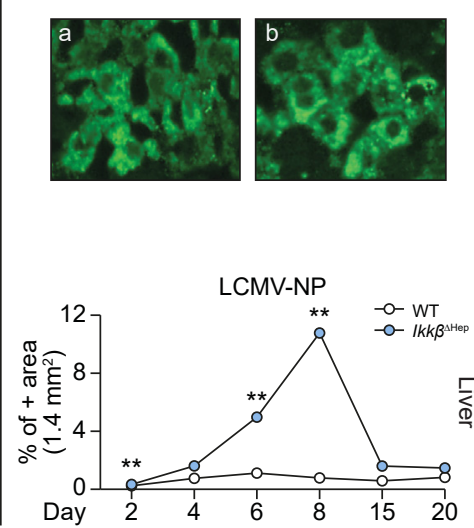

Day 2
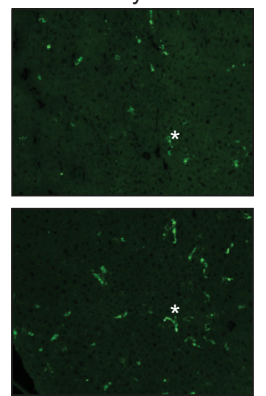

E
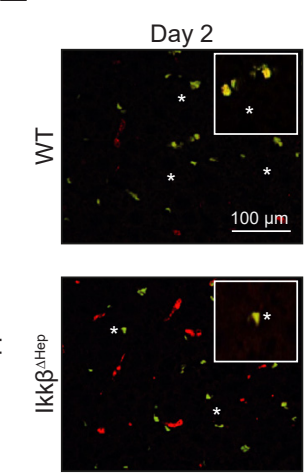

Day 4

是

$00 \mu \mathrm{m}$
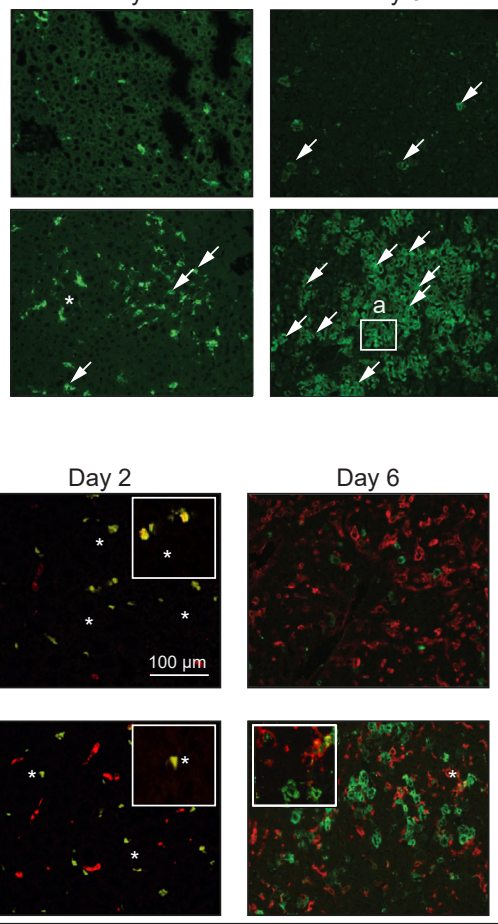

LCMV-NP-F4/80
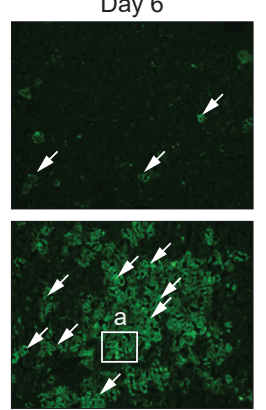

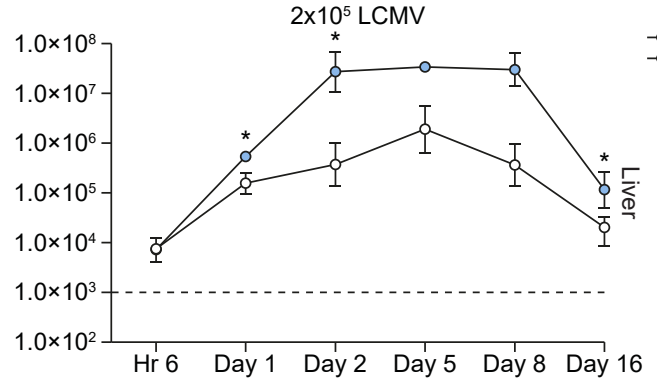

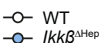

Day 8

Day 20
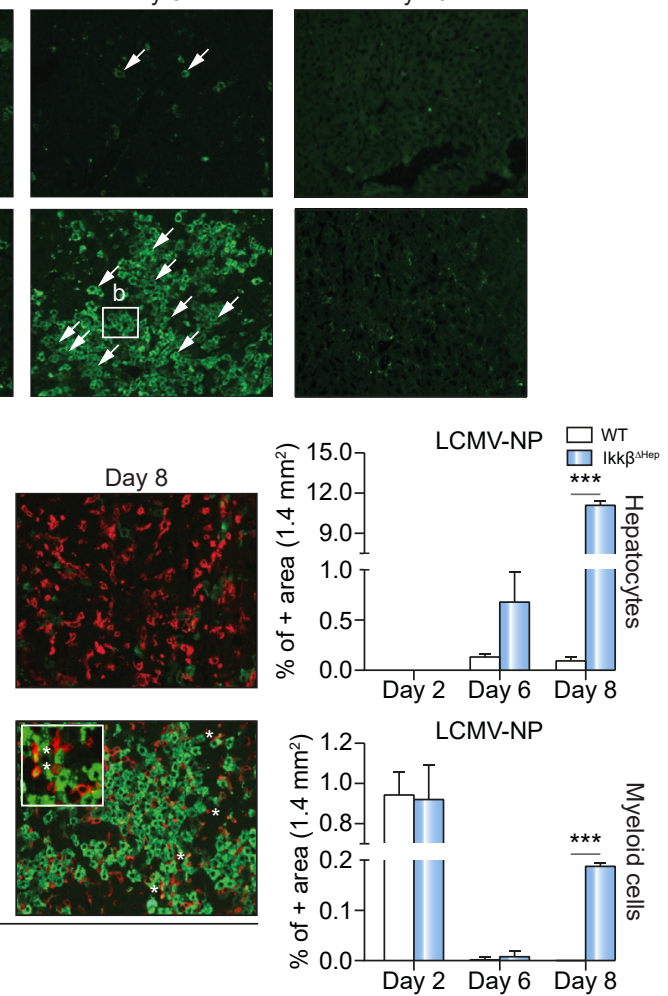

Fig. 1. LCMV-induced hepatocytic NF-kB signaling is required for overall hepatic virus control independent of KC-derived factors. (A) C57BL/6 (WT) mice were intravenously (i.v.) infected with $2 \times 10^{6}$ PFUs of LCMV-WE. $24 \mathrm{~h}$ post infection (p.i.), livers were harvested and frozen sections were stained for RelA (green), mainly localized in nuclei of hepatocytes (DAPI; blue; $n=4$ ). KCs (red) were stained using an anti-F4/80 antibody. RelA ${ }^{+}$Hepatocytes are indicated by white arrow 


\section{JOURNAL OF HEPATOLOGY}

Furthermore, expression of IFN-dependent chemokines such as CXCL9, and CXCL10 important for the chemo-attraction of immune cells such as monocytes, and $\mathrm{T}$ cells were reduced in $I k k \beta^{\Delta \mathrm{Hep}}$ livers due to hepatocyte-specific loss of canonical NF-kB signaling (Fig. 2A).

As Cxcl10 mRNA is abundantly expressed in the liver following IFN induction, it was used as a marker to monitor antiviral IFN responses following LCMV infection by sequential Cxcl10 RNA in situ hybridization and HNF4 $\alpha$ immunohistochemistry in livers of WT and $I k k \beta^{\Delta \mathrm{Hep}}$ mice (Fig. 2B). RNA expression of CXCL10 was reduced in hepatocytes (HNF4 $\alpha^{+}$cells) of $I k k \beta^{\Delta \mathrm{Hep}}$ livers, whereas the non-parenchymal compartment (e.g. KCs) still strongly expressed Cxcl10 mRNA (Fig. 2B). In contrast, in infected WT livers, both hepatocytes and nonparenchymal cells expressed Cxcl10 mRNA at high levels following infection. This highlights the importance of hepatocyte-intrinsic canonical NF- $\mathrm{KB}$ signaling in amplifying ISGs within hepatocytes following LCMV infection. Moreover, CXCL10 protein expression was reduced in $I k k \beta^{\Delta \text { Hep }}$ liver compared to WT liver at $18 \mathrm{~h}$ and $24 \mathrm{~h}$ (Fig. 2C). We did not observe a difference in mRNA expression of Ifn- $\alpha$ or Ifn- $\beta$ in WT and $I k k \beta^{\Delta \mathrm{Hep}}$ livers, thus the observed differences in ISGs most likely derive from defective IFN amplification loops in hepatocytes lacking NF-kB signaling (Fig. S2A). We further tested this reasoning by intravenously injecting IFN- $\alpha$ into WT and $I k k \beta^{\Delta \mathrm{Hep}}$ mice. Two hours later, mRNA expression of several ISGs was significantly reduced in $I k k \beta^{\Delta \text { Hep }}$ livers compared to WT livers, despite both having been exposed to similar amounts of IFN- $\alpha$ (Fig. 2D).

STAT1 is a central transcription factor which forms heterodimers with STAT2 upon activation by type I and type III IFNs. These heterodimers translocate into the nucleus and bind to IFN-stimulated response elements, thereby enhancing ISG expression. ${ }^{33}$ Strong nuclear pSTAT1 staining was observed in hepatocytes (red arrow heads in Fig. S2B) of LCMV-infected WT livers at $18 \mathrm{~h}$ p.i., which was reduced in $I k k \beta^{\Delta \mathrm{Hep}}$ hepatocytes. In contrast, non-parenchymal cells (black asterisks) were equally positive for PSTAT1 in both genotypes (Fig. S2B). Reduction of nuclear PSTAT1 in hepatocytes is consistent with lower total Stat1 mRNA expression in whole liver tissue and in hepatocytes of $I k k \beta^{\Delta \mathrm{Hep}}$ mice (Figs. $3 \mathrm{~A}$ and B). In contrast, neither STAT2 nor STAT3 phosphorylation (Figs. S2C and D) were changed in $I k k \beta^{\Delta H e p}$ livers compared to WT. To elucidate whether the reduction of pSTAT1 was indeed specific for hepatocytes, consecutive staining of HNF4 $\alpha$-pSTAT1-F4/80 liver sections derived from WT and $I k k \beta^{\Delta \mathrm{Hep}}$ mice $18 \mathrm{~h}$ p.i. was performed. These experiments and subsequent quantitative analyses indicated that in $I k k \beta^{\Delta \text { Hep }}$ livers, pSTAT1 staining is significantly reduced in $\mathrm{HNF} \alpha^{+}$hepatocytes, but remained unchanged in $\mathrm{F} 4 / 80^{+} \mathrm{KCs}$ (Fig. S2E). Taken together, these experiments indicate that hepatocyte-specific suppression of canonical NF- $\mathrm{KB}$ signaling in $I k k \beta^{\Delta \mathrm{Hep}}$ mice leads to reduced mRNA expression and phosphorylation of STAT1, and STAT1-dependent ISG induction, without affecting pStat1 levels or selected ISGs in non-parenchymal cells.

\section{Impaired ISG responses and impaired viral control in Ikk $\beta^{\Delta \mathrm{Hep}}$ livers are hepatocyte-intrinsic}

To determine whether increased viral titers and reduced ISG expression in $I k k \beta^{\Delta \mathrm{Hep}}$ livers were caused by an inability of $I k k \beta^{\Delta \text { Hep }}$ hepatocytes to integrate paracrine signaling from other cells (e.g. KCs) or by an intrinsic autocrine signaling defect, hepatocytes isolated from $I k k \beta^{\Delta \mathrm{Hep}}$ and WT livers were infected with LCMV ex vivo (Fig. 3A). Total cell lysates were analyzed for the expression of viral transcripts and ISGs. A significant increase in expression of LCMV-NP was observed in Ikk $\beta^{\Delta \text { Hep }}$ hepatocytes compared to WT, as well as a decrease in expression of several ISGs (Fig. 3B).

The importance of NF-kB signaling in amplifying ISGs was further verified by treating cultured primary hepatocytes ex vivo with IFN- $\alpha$. IKK $\beta$-deficient hepatocytes displayed reduced induction of ISGs compared to WT hepatocytes (Fig. 3C). Furthermore, no significant differences were observed in Ifn- $\alpha$ and Ifn- $\beta$ mRNA expression in ex vivo cultivated, LCMV-infected hepatocytes from $I k k \beta^{\Delta \mathrm{Hep}}$ and $\mathrm{WT}$ at $18 \mathrm{~h}$ and $24 \mathrm{~h}$ p.i. (Fig. S2F). Thus, hepatocyte-intrinsic canonical NF- $\mathrm{KB}$ signaling is indispensable for efficient expression of ISGs.

\section{Hepatic ISGs can be expressed in the absence of hepatic APCs or KCs}

To further test the interplay between KCs and hepatocytes in the generation of hepatic immune responses, mice were treated with clodronate-containing or empty (PBS) liposomes prior to LCMV infection. Viral titers were measured in livers of both groups at 1-day p.i. An increase in viral titers from mice with clodronate depletion was found at 1-day p.i., suggesting that phagocytic immune cells such as KCs are required for optimal control of initial viral replication in hepatocytes (Figs. S3A and B). Despite significant differences in the mRNA expression of Mx1, Oas2, and Oas3 in the absence of myeloid cells, expression levels of Ifn- $\beta$ and other ISGs such as Isg15, Ifit1 and Cxcl10 were not significantly changed. Thus, early after infection, several hepatic ISGs can be expressed in the absence of KCs or hepatic APCs (Fig. S3C).

\section{LCMV accumulates in hepatocytes from mice with defective hepatocyte-specific IFN signaling}

Our results indicated that defective NF- $\mathrm{KB}$ signaling in hepatocytes dampened IFN responses in liver tissue and facilitated enhanced LCMV replication. To determine the relative contribution of liver parenchymal- or myeloid-specific IFN signaling to viral control, mice lacking IFNAR1 selectively in liver

heads. RelA ${ }^{+}$KCs are denoted by white asterisks. (B) C57BL/6 and $I k k \beta^{\Delta H e p}$ mice were infected i.v. with $2 \times 10^{6}$ PFUs of LCMV-WE (n $=3$ ). Livers were isolated starting from $3 \mathrm{~h}$ until $24 \mathrm{~h}$ p.i and frozen liver sections of infected mice were stained for RelA (green) and DAPI (blue) to stain nuclei. Representative images from $12 \mathrm{~h}$ p.i. are shown. Livers of uninfected WT mice were used as controls. Percentage of RelA ${ }^{+}$area is quantified (right panel). (C) WT and $I k k \beta^{\Delta H e p}$ mice were i.v. infected with $1 \times 10^{5}$ PFUs or $2 \times 10^{5}$ PFUs of LCMV-WE ( $n=3-4$ for each time point). Livers from infected mice were harvested at indicated time points and analyzed for infectious virus using a virus plaque-forming assay ( $\mathrm{n}=3-5$ per liver tissue sample). Virus titers were normalized to mg of liver tissue. (D) (E) WT and $I k k \beta^{\Delta \text { Hep }}$ mice were infected i.v. with $2 \times 10^{6}$ PFUs of LCMV-WE $(n=4)$. Livers were isolated at different time points p.i. Frozen liver sections from infected mice were stained for LCMV-NP (green) and F4/80 (red). Co-localization signal is indicated in yellow. Representative images from indicated time points are shown. Yellow asterisks indicate non-parenchymal liver cells (e.g. KCs) positive for LCMV-NP. Error bars indicate mean \pm SEM, ${ }^{*} p \leq 0.05$, ${ }^{* *} p \leq 0.01$, ${ }^{* * *} p \leq 0.001$; unpaired Student's $t$ test. ISGs, interferon-stimulated genes; KCs, Kupffer cells; LCMV, lymphocytic choriomeningitis virus; NP, nuclear protein; PFUs, plaque-forming units; WT, wild-type. 
A
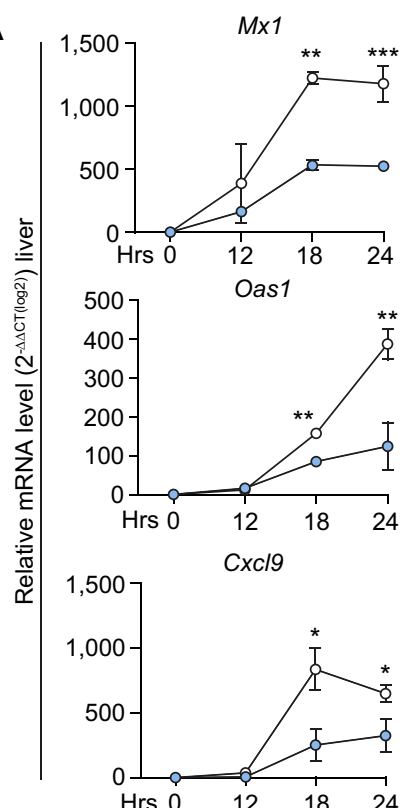
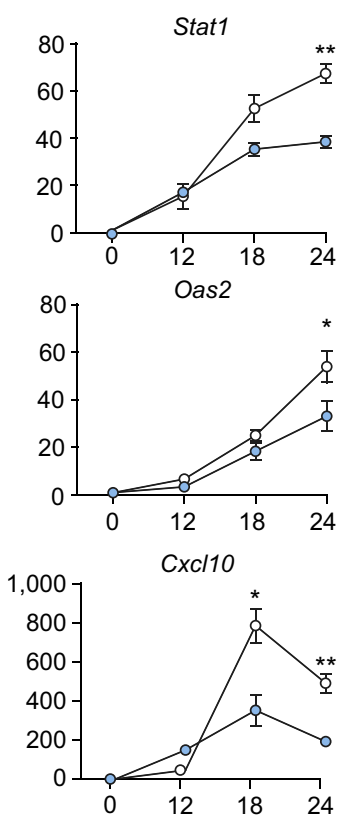
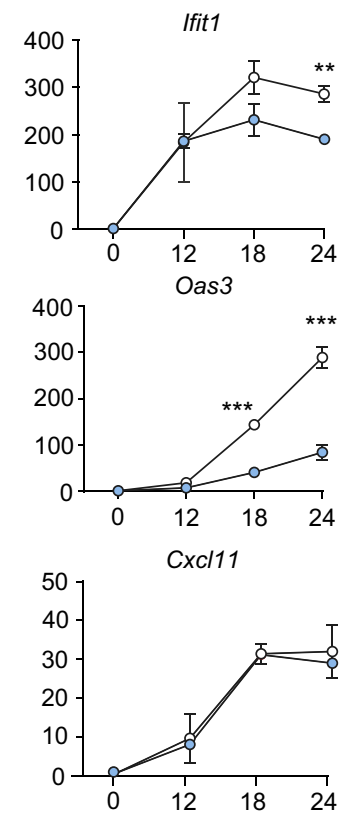

$\mathrm{lkk} \beta^{\Delta \mathrm{Hep}}$
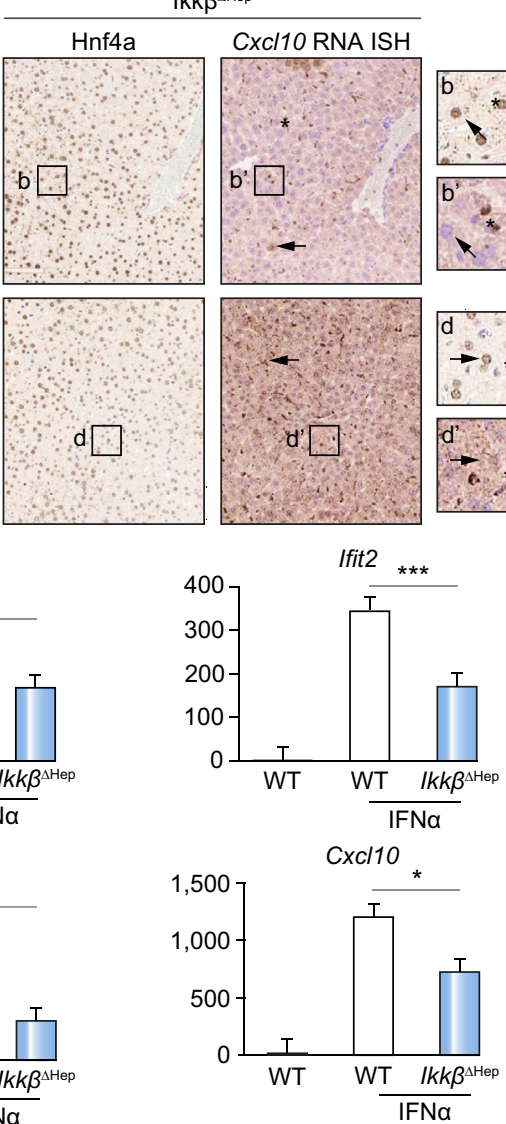
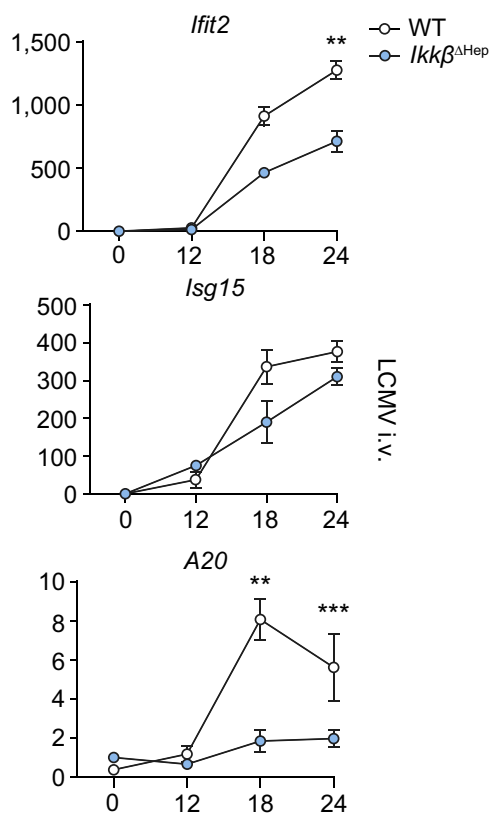

C
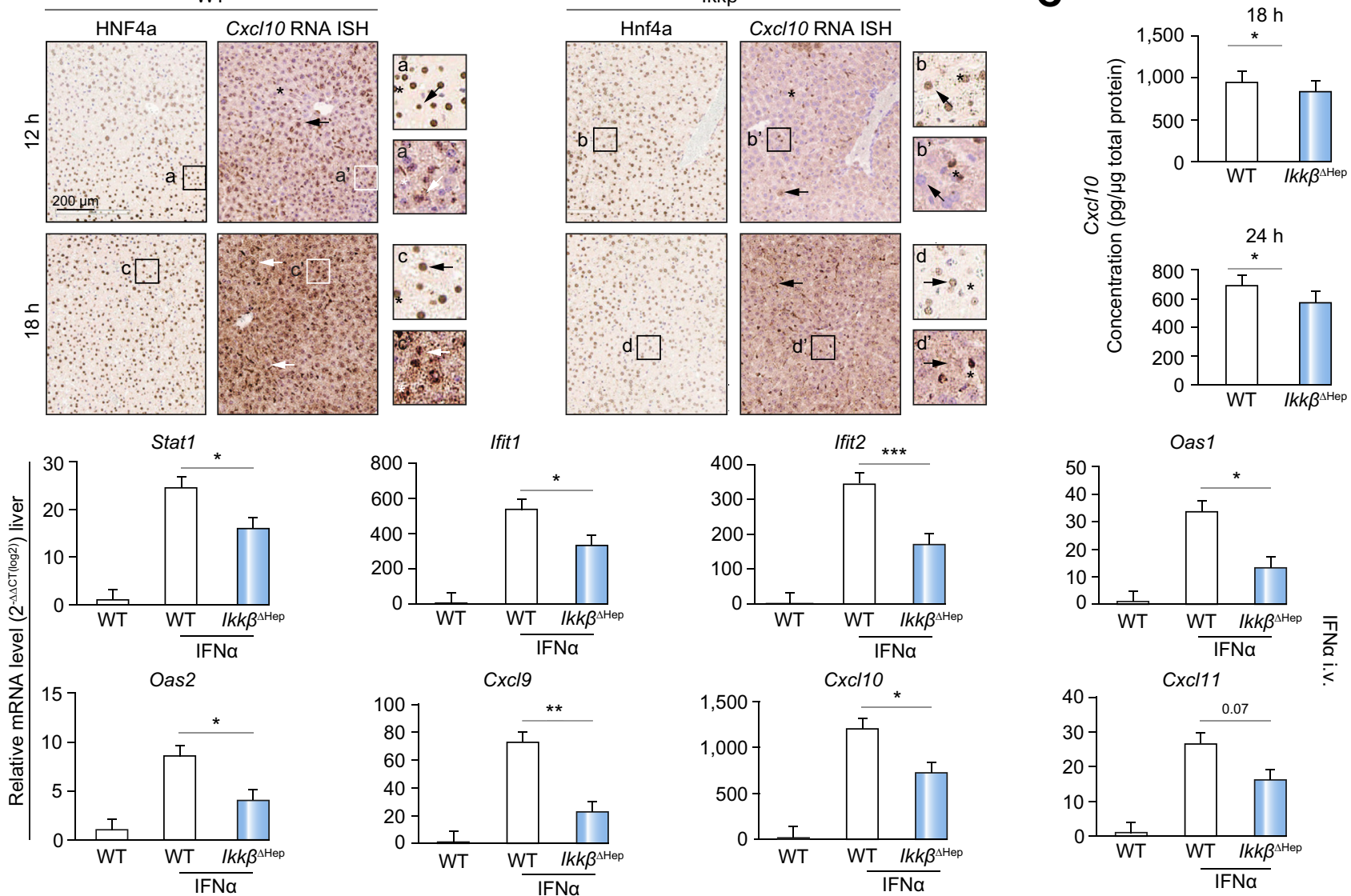

Fig. 2. Loss of NF-kB signaling in hepatocytes leads to impaired interferon responses. WT and $I k k \beta^{\Delta \mathrm{Hep}}$ mice were i.v. infected with $2 \times 10^{6} \mathrm{PFUs}$ of LCMV-WE and a time course was performed from $0-24 \mathrm{~h}$ ( $\mathrm{n}=3-4$ per each time point). (A) Livers were isolated at indicated time points and analyzed for ISG expression through qRT-PCR. (B) Cxcl10 (IP10) mRNA expression from LCMV-WE infected livers analyzed by in situ hybridization and HNF4 $\alpha$ staining was performed on consecutive slides. Red triangle: hepatocytes. Black asterisks: non-parenchymal cells (e.g. KCs). Arrows indicate the positive cells. (C) CXCL10 protein was analyzed by ELISA on total liver extract and is presented as average quantity of CXCL10 per $\mu \mathrm{g}$ of total protein. (D) WT and Ikk $\beta^{\Delta \mathrm{Hep}}$ mice were given $500 \mathrm{U}$ of IFN- $\alpha$ i.v. $(\mathrm{n}=3)$, compared to untreated WT livers and tested for the expression of ISGs through qRT-PCR. Error bars indicate mean \pm SEM, ${ }^{*} p \leq 0.05,{ }^{* *} p \leq 0.01,{ }^{* * *} p \leq 0.001$; unpaired Student's $t$ test. ISGs, interferon-stimulated genes; KCs, Kupffer cells; LCMV, lymphocytic choriomeningitis virus; NP, nuclear protein; PFUs, plaqueforming units; qRT-PCR, quantitative reverse transcription PCR; WT, wild-type. 

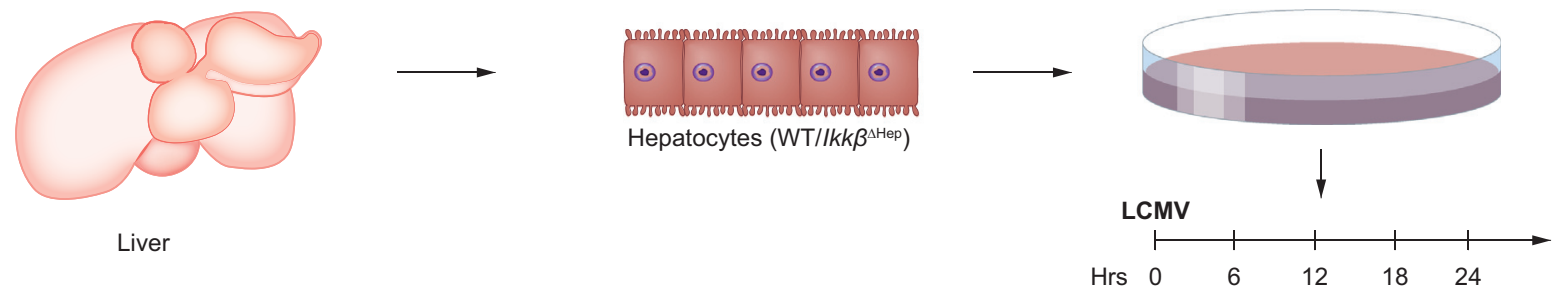

B
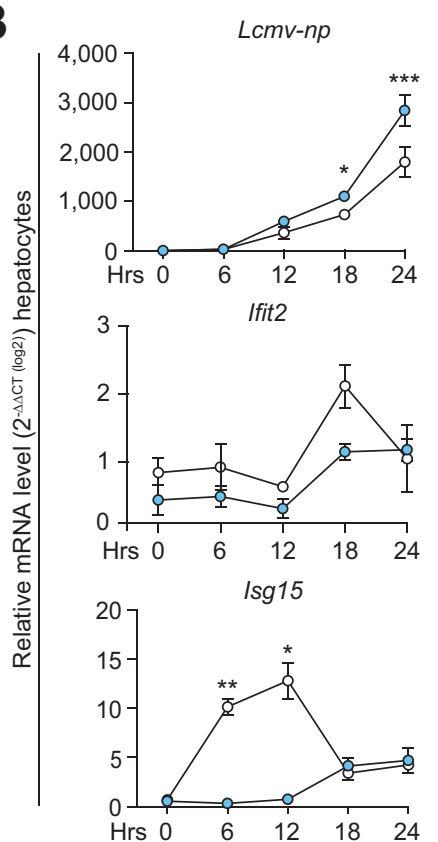

C

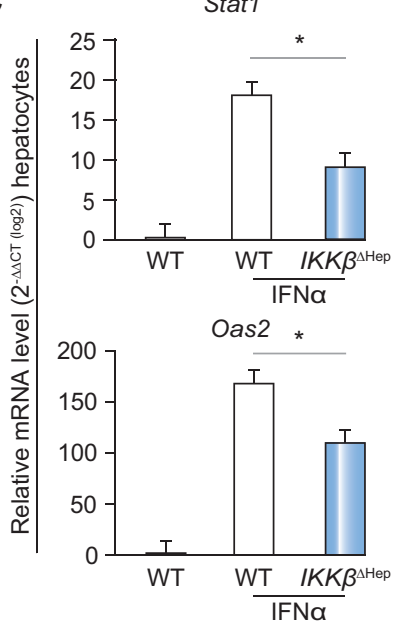

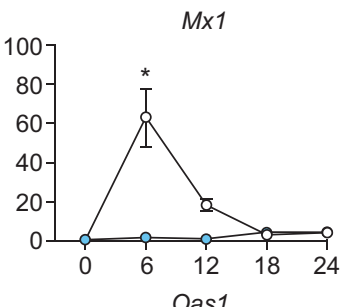
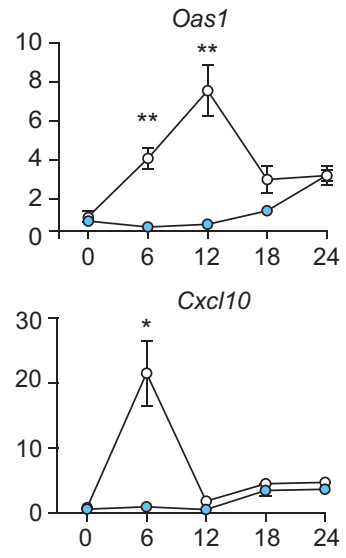

Ifit1
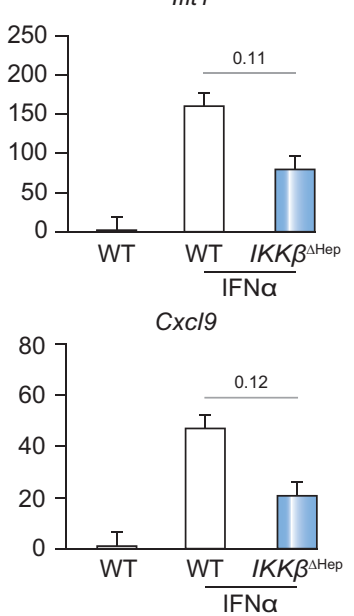
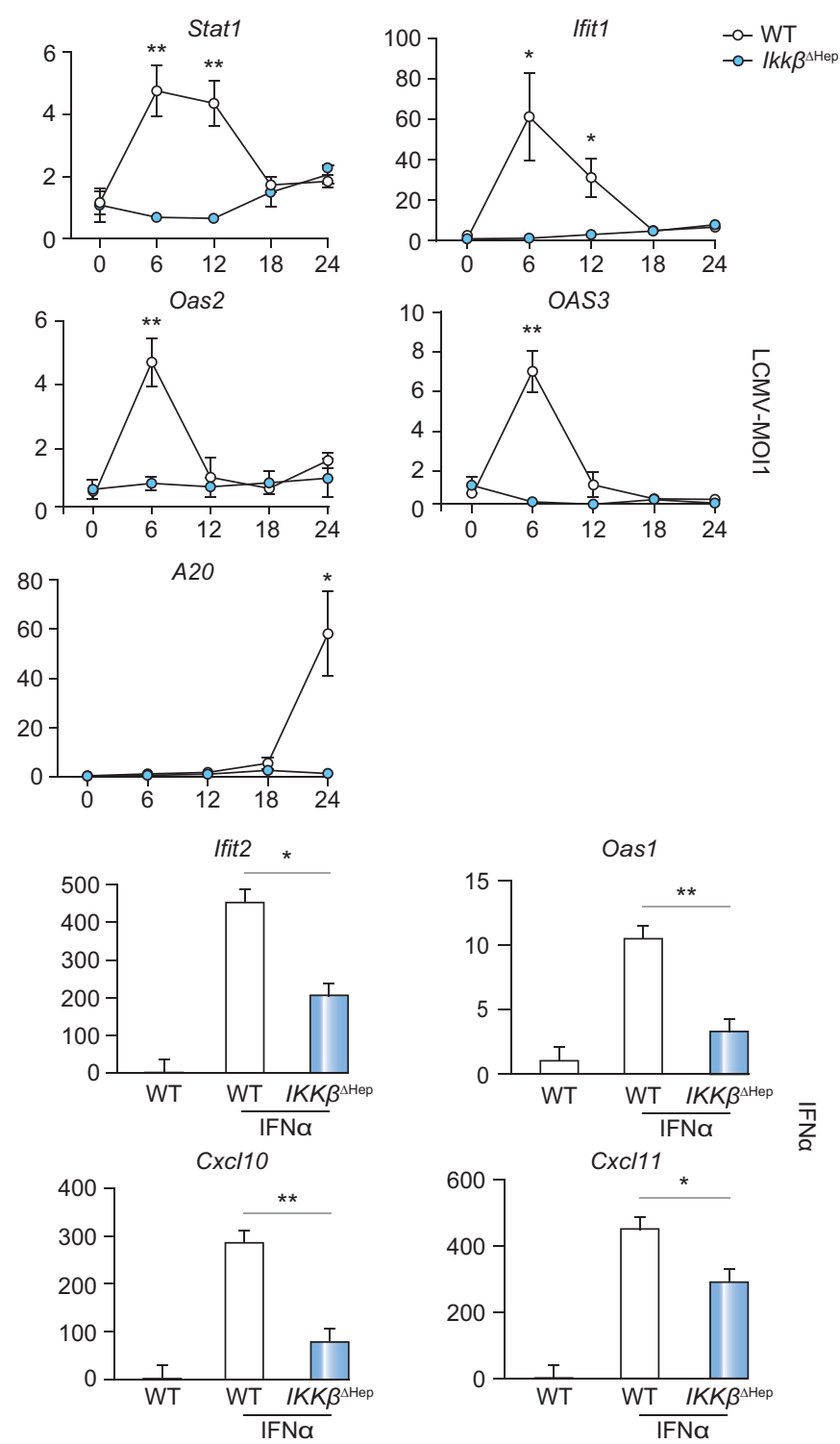

Fig. 3. Impaired ISG responses and viral control in Ikk $\boldsymbol{\beta}^{\Delta \mathbf{H e p}}$ livers is hepatocyte-intrinsic. (A) Schematic model describing the experiment. Hepatocytes were isolated from livers of WT and Ikk $\beta^{\Delta \text { Hep }}$ mice and infected ex vivo with LCMV-WE $(\mathrm{MOI}=1)$. (B) RNA was extracted at the indicated time points from isolated hepatocytes and analyzed for LCMV NP, GP and ISG expression. (C) Hepatocytes were isolated from WT and Ikk $\beta^{\Delta \mathrm{Hep}}$ mice and treated ex vivo with $250 \mathrm{U}$ of IFN- $\alpha$. RNA was extracted from hepatocytes at $12 \mathrm{~h}$ post treatment and analyzed for the expression of ISGs. Error bars indicate mean \pm SEM, ${ }^{*} p \leq 0.05$, ${ }^{* *} p \leq 0.01$, ${ }^{* * *} p \leq 0.001$; unpaired Student's $t$ test. GP, glycoprotein; ISGs, interferon-stimulated genes; KCs, Kupffer cells; LCMV, lymphocytic choriomeningitis virus; MOI, multiplicity of infection; NP, nuclear protein; PFUs, plaque-forming units; WT, wild-type.

parenchymal cells $\left(\text { Ifnar }^{\Delta \mathrm{Hep}}\right)^{20,26}$ or myeloid cells, including KCs $\left(\text { Ifnar }^{\Delta \text { Myel }}\right)^{26,34}$ were infected with LCMV. The efficacy and specificity of Ifnar1 deletion was analyzed in hepatocytes, KCs or hepatic inflammatory myeloid cells by PCR. Ifnar was deleted with high efficacy in hepatocytes and KCs, but less so in liverinfiltrating monocytes (Fig. S3D). 
A

B

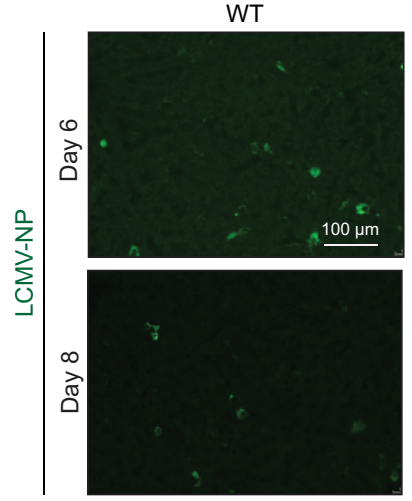

WT

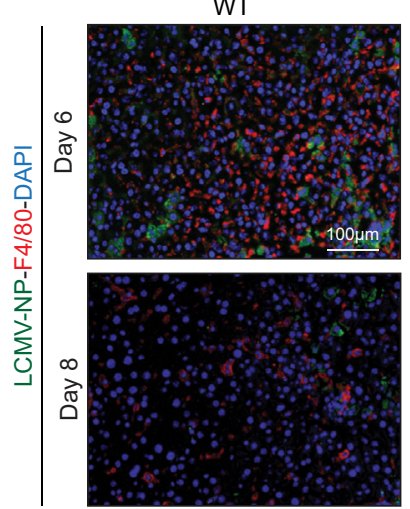

$I k k \beta^{\text {Hнер }}$

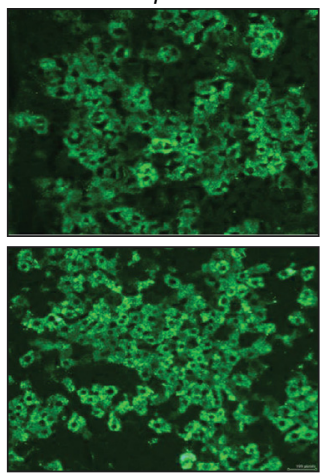

$I k k \beta^{\Delta \text { Hep }}$
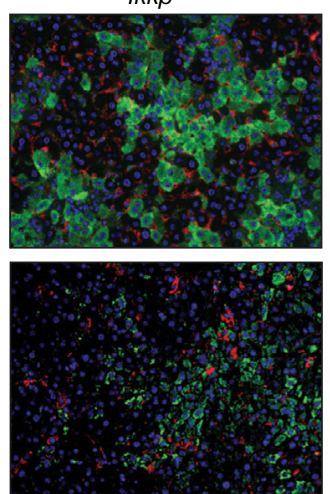
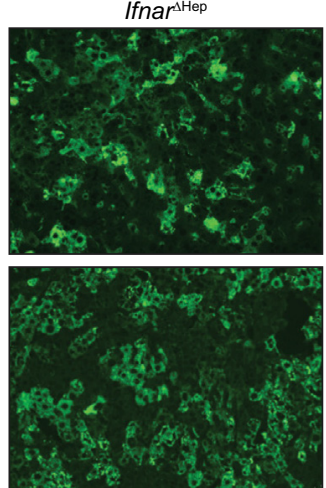

Ifnar ${ }^{\text {HHep }}$
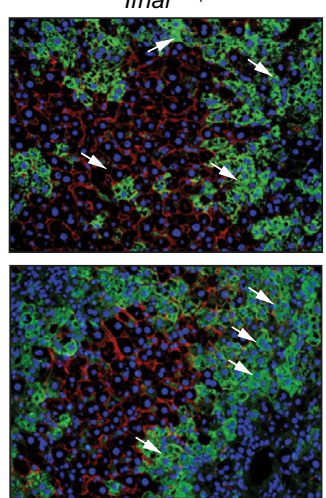

C
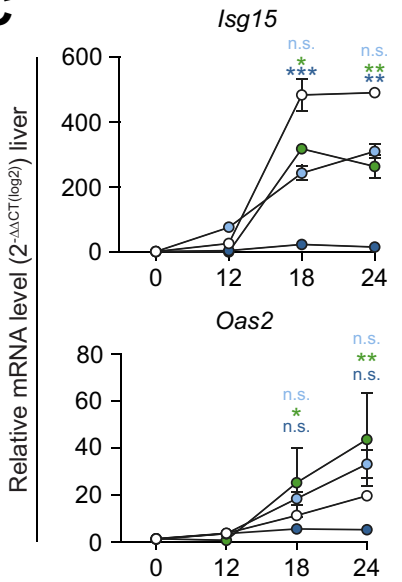
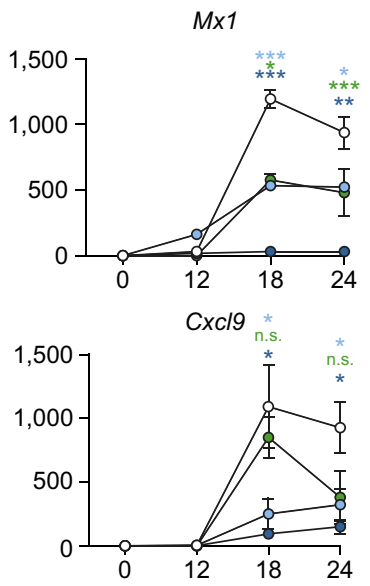
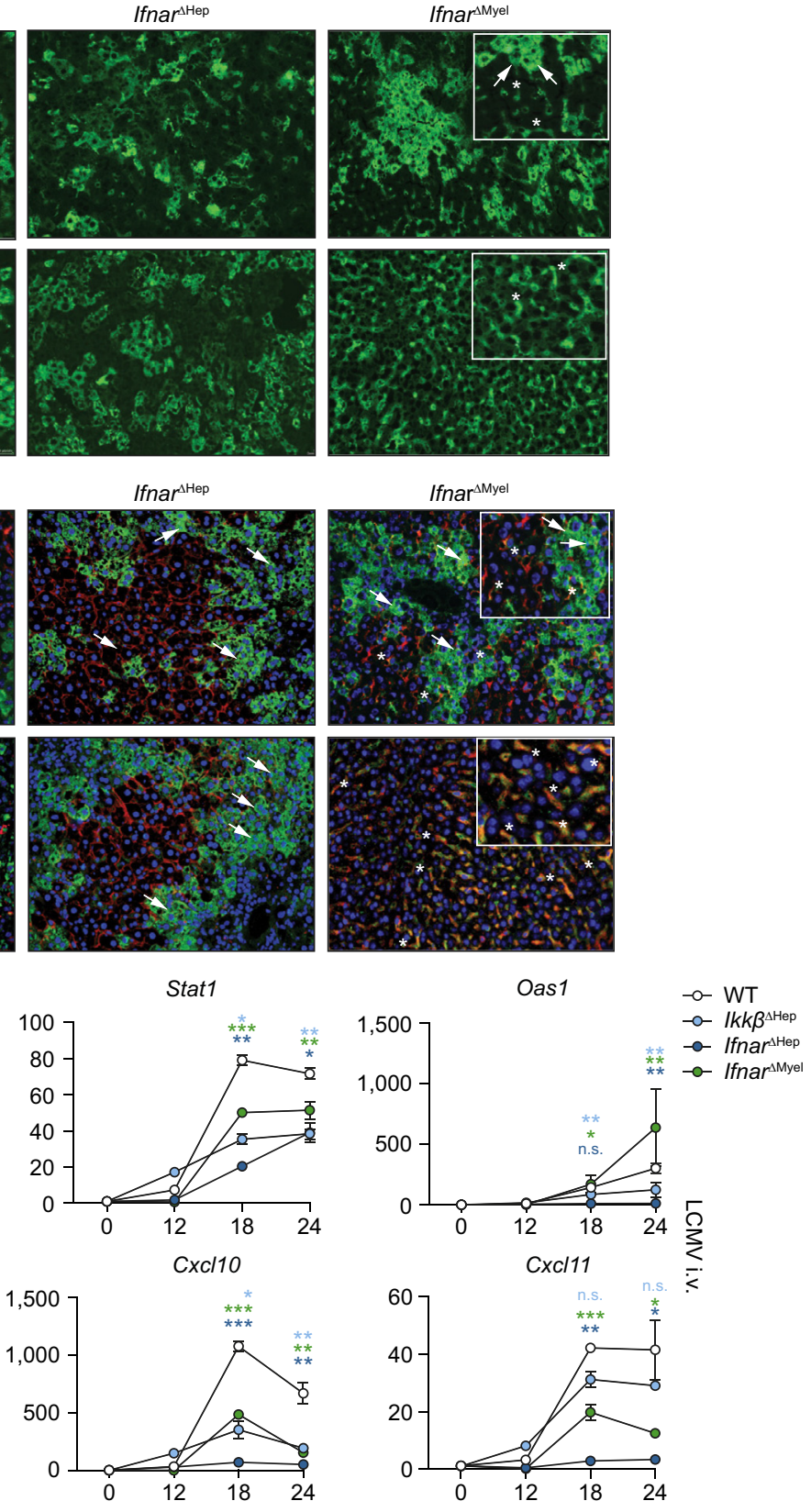

D

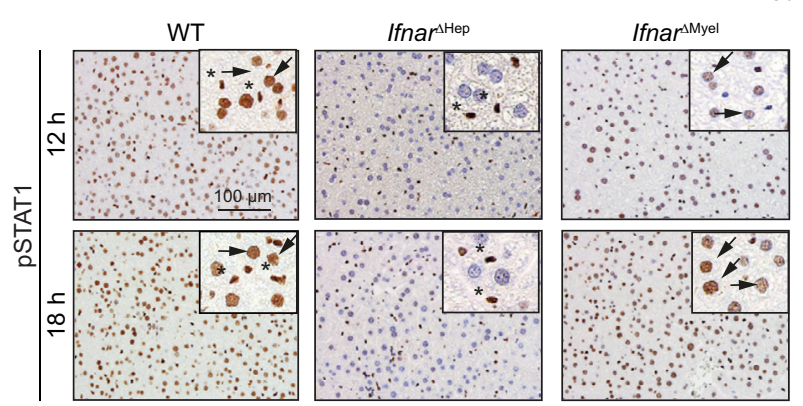

E
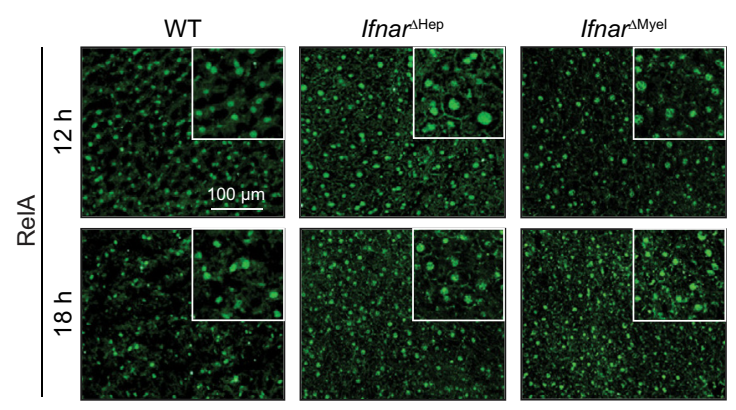

Fig. 4. LCMV accumulates in hepatocytes from mice with defective hepatocyte-specific interferon signaling. WT, Ikk $\beta^{\Delta \mathrm{Hep}}$, Ifnar ${ }^{\Delta \mathrm{Hep}}$ and Ifnar ${ }^{\Delta \mathrm{Myel}}$ mice were i.v. infected with $2 \times 10^{6}$ PFUs of LCMV-WE and tested for the distribution of LCMV-NP expression ( $\mathrm{n}=3-4$, each time point). (A) Livers were isolated at the indicated time points and stained for LCMV-NP. Representative images are shown. White asterisks: non-parenchymal liver cells LCMV-NP'. White arrow heads: hepatocytes LCMV-NP+ . (B) Livers of infected mice of the indicated genotypes were stained with F4/80 (red), LCMV-NP (green), DAPI (blue). White arrow heads: hepatocytes. Yellow asterisks: KCs. (C) Livers were isolated at indicated time points and analyzed for ISG expression through qRT-PCR. (D, E) Histological analysis 


\section{JOURNAL OF HEPATOLOGY}

Upon infection, LCMV-NP protein expression was analyzed in Ifnar $^{\Delta \mathrm{Hep}}$, Ifnar ${ }^{\Delta \mathrm{Myel}}, I k k \beta^{\Delta \mathrm{Hep}}$, and WT livers. Similar to I $k k \beta^{\Delta \mathrm{Hep}}$, livers of Ifnar ${ }^{\Delta \mathrm{Hep}}$ mice displayed LCMV-positive hepatocyte clusters at day 6 and 8 p.i. (Fig. 4A), supporting our hypothesis that a robust early hepatocyte-intrinsic IFN response (amplified by IKK $\beta$ ) through IFNAR is required for efficient ISG expression and viral control in the liver. Notably, infected Ifnar ${ }^{\Delta \text { Myel }}$ mice displayed impaired protection against viral replication, as both KCs and hepatocytes were strongly positive for LCMV-NP at day 6 p.i. However, the intensity of LCMV-NP expression in Ifnar ${ }^{\triangle \mathrm{Myel}}$ mice decreased in hepatocytes by day 8 p.i. and was primarily localized to $\mathrm{F} 4 / 80^{+}$cells (Figs. $4 \mathrm{~A}$ and $\mathrm{B}$ ), indicating that hepatocytes respond both to paracrine IFN signaling from KCs and to autocrine IFN signaling from hepatocytes (Fig. 4B).

\section{Hepatocytes are the major producers of ISGs in the liver following LCMV infection}

To further delineate the functional importance of hepatocyte- $v s$. myeloid cell-mediated IFN production and IFN responses, whole liver lysates from WT, Ikk $\beta^{\Delta \mathrm{Hep}}$, Ifnar ${ }^{\Delta \mathrm{Hep}}$, and Ifnar ${ }^{\Delta \text { Myel }}$ mice were analyzed for IFN and ISG expression up to $24 \mathrm{~h}$ after LCMV infection. Overall, Ifn- $\beta$ mRNA expression in livers was decreased during early phases of LCMV-WE infection (12 h p.i.) in Ifnar ${ }^{\text {Myel }}$ livers compared to Ifnar ${ }^{\Delta \mathrm{Hep}}, I k k \beta^{\Delta \mathrm{Hep}}$, and WT livers but not at later time points (Fig. S3E). This suggests that efficient, early IFN$\beta$ expression depends on KCs and myeloid IFNAR expression. Moreover, ISGs such as Isg15, Mx1, and Stat1, as well as IFNinduced chemokines such as CXCL10 were more strongly upregulated in WT compared to Ifnar ${ }^{\Delta \mathrm{Hep}}$ (strongest reduction), Ifnar ${ }^{\Delta \text { Myel }}$ and Ikk $\beta^{\Delta \text { Hep }}$ livers at $18 \mathrm{~h}$ p.i. (Fig. 4 C). Although ISG expression was decreased in Ifnar ${ }^{\Delta \text { Myel }}$ compared to WT livers, the expression levels were similar to Ikk $\beta^{\Delta \mathrm{Hep}}$ livers and significantly higher when compared to Ifnar ${ }^{\Delta \mathrm{Hep}}$ (Fig. 4C).

Immunohistochemical analyses revealed reduced pSTAT1 signals in hepatocyte nuclei of LCMV-infected Ifnar ${ }^{\Delta \text { Hep }}$ livers compared to WT at $12 \mathrm{~h}$ and $18 \mathrm{~h}$ p.i., whereas pSTAT1 in myeloid cells remained unaffected (Fig. 4D). In contrast, Ifnar ${ }^{\Delta \text { Myel }}$ livers displayed reduced pSTAT1 in both hepatocytes and myeloid cells at $12 \mathrm{~h}$ p.i. (Figs. 4D and S3F), indicative of a delayed IFN response in hepatocytes due to impaired IFNAR signaling in myeloid cells. These observations were confirmed by consecutive staining of HNF4 $\alpha$-pSTAT1-F4/80 in livers of WT and Ifnar ${ }^{\Delta \text { Myel }}$ mice. Our data indicate that in Ifnar ${ }^{\Delta \text { Myel }}$ mice livers, pSTAT1 staining is strongly reduced in $\mathrm{F} 4 / 80^{+} \mathrm{KCs}$, and significantly lowered in HNF4a $\alpha^{+}$hepatocytes, in comparison to WT mice (Figs. S2E and S3G). Of note, hepatocyte-specific RelA translocation occurred in WT, Ifnar ${ }^{\Delta \mathrm{Hep}}$, and Ifnar ${ }^{\Delta \mathrm{Myel}}$ with similar efficacy (Fig. 4E). This indicates that with intact NF-kB signaling, hepatocytes integrate paracrine IFNAR signaling from the neighboring KCs and initiate an antiviral response at an early stage, as well as initiating intrinsic autocrine IFNAR signaling.

\section{Depletion of IKK $\beta$ in hepatocytes reduces LCMV-induced chemokine expression and immune cell influx}

Efficient activation of IFN signaling in hepatocytes is NF-KBdependent and is important for cell-intrinsic control of viral replication and dissemination. IFN responses also promote cytotoxic $\mathrm{CD}^{+} \mathrm{T}$ cell responses ${ }^{35}$ and may inhibit or suppress regulatory $\mathrm{CD}^{+}{ }^{+} \mathrm{T}$ cell responses during acute LCMV infections. ${ }^{36}$ IFN and NF-KB-driven expression of CXCR3 ligand supports the infiltration of cytotoxic $\mathrm{CD}^{+} \mathrm{T}$ cells to sites of inflammation, and hepatocytes are a known source of CXCR3 ligands such as CXCL9, CXCL10 and CXCL11 during viral infections and autoimmune disease. ${ }^{37-39}$ Since we observed an increased viral load in $I k k \beta^{\Delta}$ Hep compared to WT livers at day 6 and 8 p.i, we investigated whether alterations in chemokine expression or subsequent intrahepatic immune cell attraction could be detected.

Real time PCR analysis of LCMV-infected liver homogenates revealed reduced expression of chemokines such as CCL5, CXCL9, CXCL10 and CXCL11 at 6 and 8 days p.i., but not at 15 days p.i., in $I k k \beta^{\Delta \mathrm{Hep}}$ mice compared to WT (Fig. 5A). To determine whether intrahepatic recruitment of $\mathrm{CD}^{+} \mathrm{T}$ cells was consequently affected, we analyzed the abundance of $\mathrm{CD}^{+} \mathrm{T}$ cells in livers of LCMV-infected I $k k \beta^{\Delta \text { Hep }}$ and WT mice via immunohistochemistry. Densitometric analyses of images indicated significant lower numbers of $\mathrm{CD}^{+} \mathrm{T}$ cells at days 6 and 8 p.i. in livers of Ikk $\beta^{\Delta \text { Hep }}$ mice (Fig. 5B). At 15 and 20 days p.i., no significant differences were observed in the abundance of $\mathrm{CD} 8^{+} \mathrm{T}$ cells, highlighting similar $\mathrm{CD}^{+} \mathrm{T}$ cell recruitment efficacy at later time points in both genotypes (Fig. 5C). Moreover, FACS analysis revealed a reduction in the number of $\mathrm{LCMV}$-specific $\mathrm{CD} 8^{+} \mathrm{T}$ cells at day 6 p.i. in livers of $I k k \beta^{\Delta \mathrm{Hep}}$ mice (Fig. 5D).

CXCR3 ligands also initiate robust inflammatory cascades by interacting with their cognate receptor, highly expressed on immune cells such as KCs, dendritic cells, neutrophils, natural killer cells and natural killer $T$ cells. Since we identified a decrease in hepatocyte-derived CXCL10 during both the innate (Fig. 2A) and adaptive phases (Fig. 5A) of the immune response against LCMV infection, we reasoned that innate immune cell infiltration and activation in livers during the early and late phases of infection could be affected in Ikk $\beta^{\Delta \mathrm{Hep}}$ mice. Interestingly, we observed reduced mRNA expression of $\mathrm{Ccl} 5, \mathrm{Cd} 14$, iNos, Cd11b, Ly6C and Cd207 during the early phase of LCMV-WE infection (Fig. S4A). The expression of Ccl4, Ccr5 and Ly6C was further reduced during the late phase (Fig. S4B). Moreover, we observed a significant reduction in intrahepatic infiltration of $\mathrm{CD}^{+} 8^{+}$monocytes and $\mathrm{MHCII}^{+}$cells, plausibly due to reduced chemokine expression during late-stage LCMV-WE infection (Fig. S4C). Of note, $\mathrm{F} 4 / 80^{+} \mathrm{KCs}$ were not significantly altered in number in both genotypes (Fig. S4C). These results were confirmed by staining liver sections using a Kupffer cell-specific marker, Clec4F (Fig. S4D). Taken together, these experiments identified a dual role for hepatocyte-specific canonical NF-kB signaling in i) inducing an adequate cell-intrinsic early, antiviral response and ii) subsequent viral clearance by attracting adaptive and innate immune cells to the liver.

\section{Loss of NF- $\mathrm{kB}$ signaling in differentiated HepaRG cells impairs ISG expression post-treatment with IFN- $\alpha$ or following HDV infection}

We demonstrated that ablation of IKK $\beta$ specifically in hepatocytes significantly impairs an early, efficient viral response to

of the indicated genotypes for nuclear translocation of pSTAT1 or RelA at $12 \mathrm{~h}$ and $18 \mathrm{~h}$ p.i. Black arrow heads: hepatocytes. Black asterisks: non-parenchymal liver cells. Error bars indicate mean $\pm \mathrm{SEM},{ }^{*} p \leq 0.05,{ }^{* *} p \leq 0.01,{ }^{* * *} p \leq 0.001$; unpaired Student's $t$ test. LCMV, lymphocytic choriomeningitis virus; NP, nuclear protein; PFUs, plaque-forming units; qRT-PCR, quantitative reverse transcription PCR; WT, wild-type. 
A
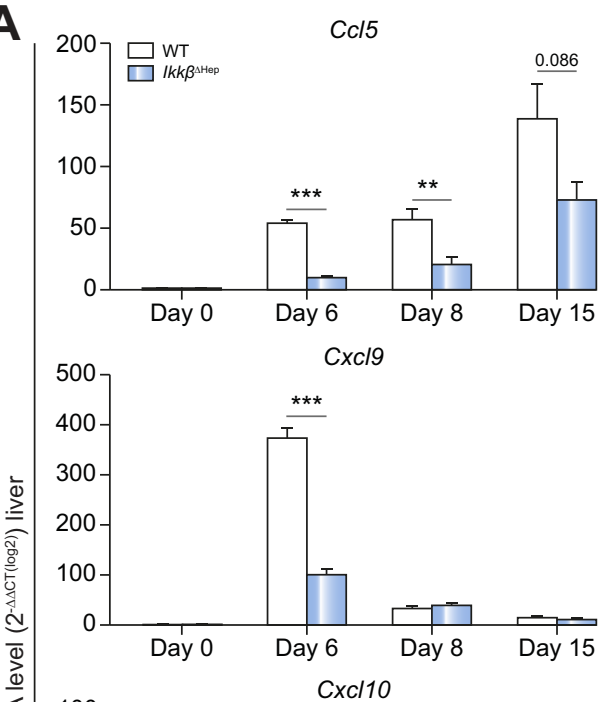

${ }^{100}{ }^{C x C l 10} \quad$ C
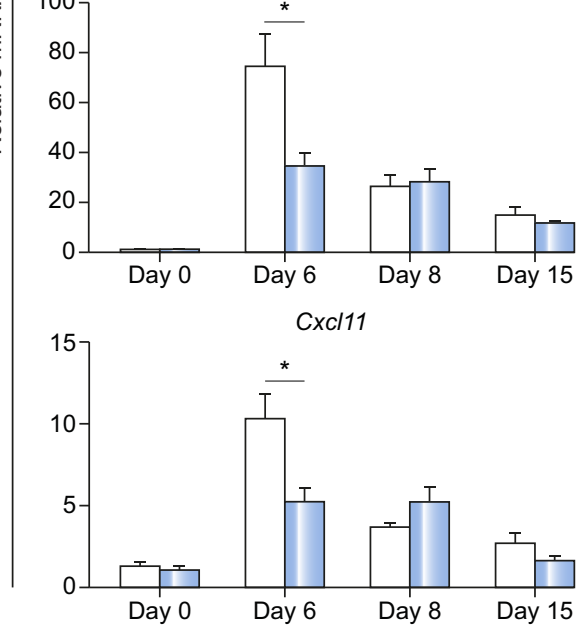

B
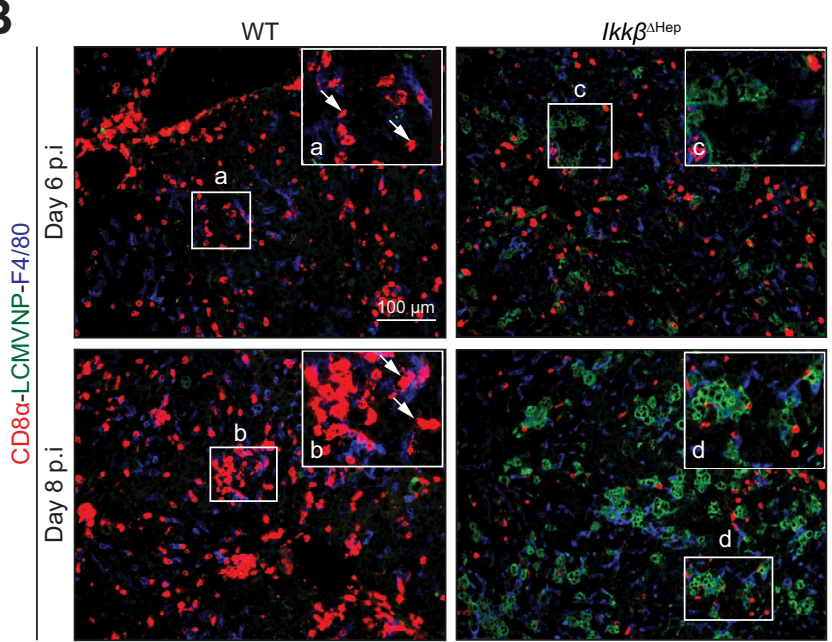

C
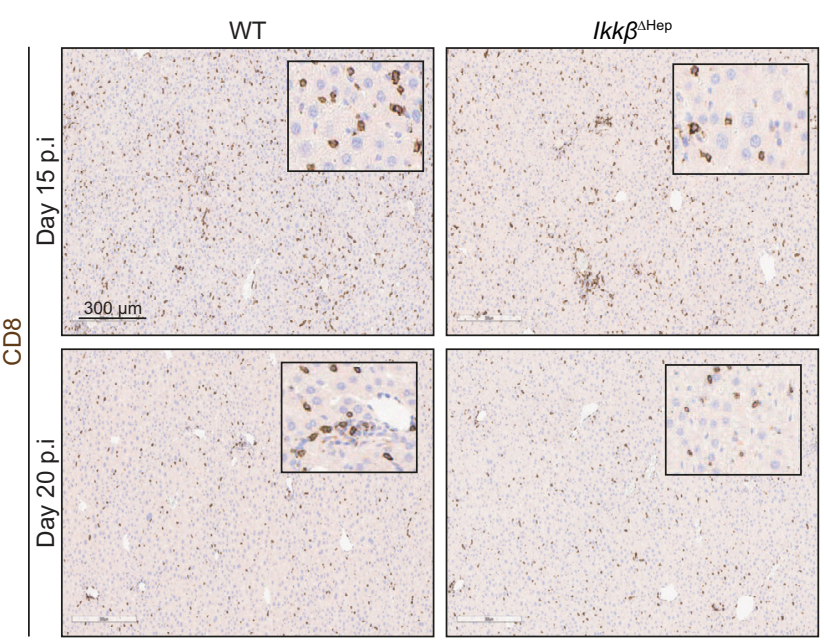

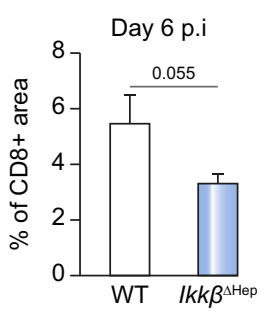

Day 8 p.i

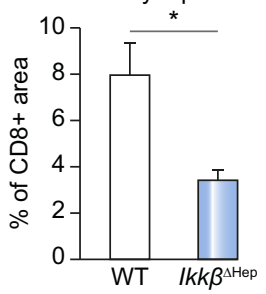

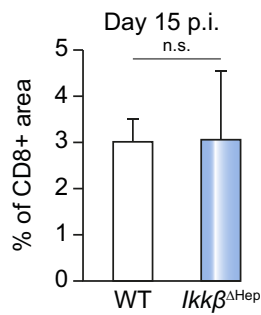

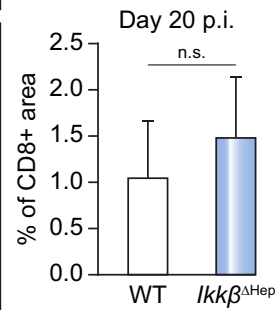

D
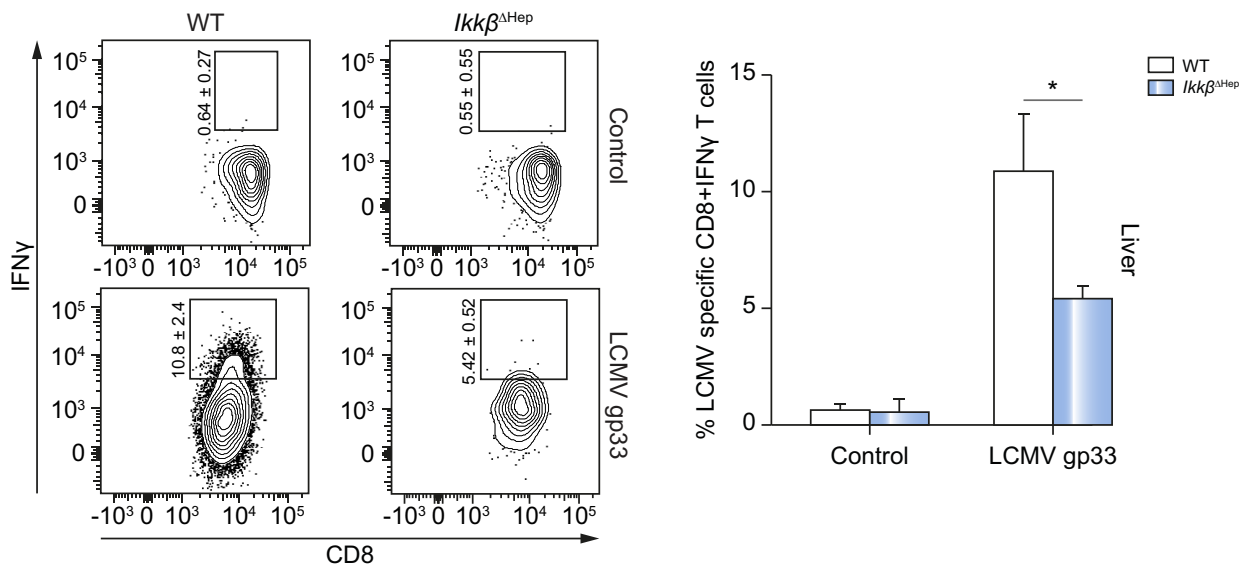

Fig. 5. Depletion of IKK $\beta$ in hepatocytes reduces hepatic immune cell influx and adaptive immune responses. WT and $I k k \beta^{\Delta \mathrm{Hep}}$ mice were infected i.v. with $2 \times 10^{6}$ PFUs of LCMV-WE ( $n=6$ each time point) and analyzed. (A) Livers were analyzed for the expression of selected chemokines by qRT-PCR. (B) Frozen liver sections were stained for CD8 ${ }^{+}$T cells (red), LCMV-NP (green), and F4/80 (blue). Arrows indicate the positive cells. (C) Paraffin-embed liver sections were stained by immunohistochemistry for $\mathrm{CD}^{+} \mathrm{T}$ cells. $(\mathrm{B}, \mathrm{C})$ Representative images from indicated time points are shown. Total CD8 ${ }^{+}$area was densitometrically quantified for each genotype. (D) Flow cytometry analysis of IFN- $\gamma^{+} \mathrm{CD}^{+} \mathrm{T}$ cells isolated from the livers of LCMV-infected WT and Ikk $\beta^{\Delta \mathrm{Hep}}$ mice 6 days p.i. and stimulated with LCMV gp33 peptide or control peptide ( $\mathrm{n}=6$ each genotype). Error bars indicate mean \pm SEM, ${ }^{*} p \leq 0.05,{ }^{* *} p \leq 0.01,{ }^{* * *} p \leq 0.001$; unpaired Student's $t$ test. LCMV, lymphocytic choriomeningitis virus; NP, nuclear protein; PFUs, plaque-forming units; qRT-PCR, quantitative reverse transcription PCR; WT, wild-type. 

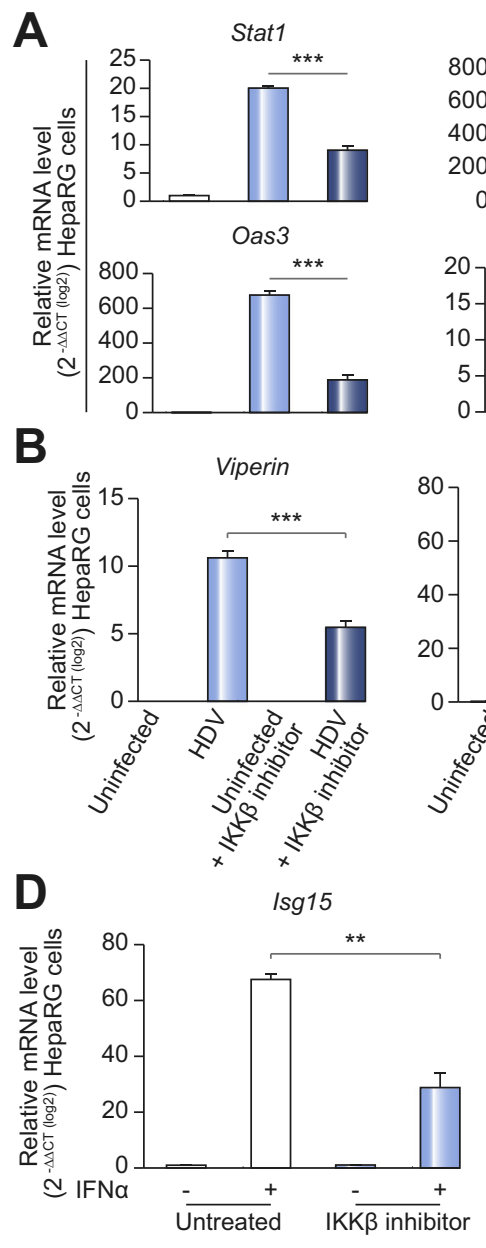
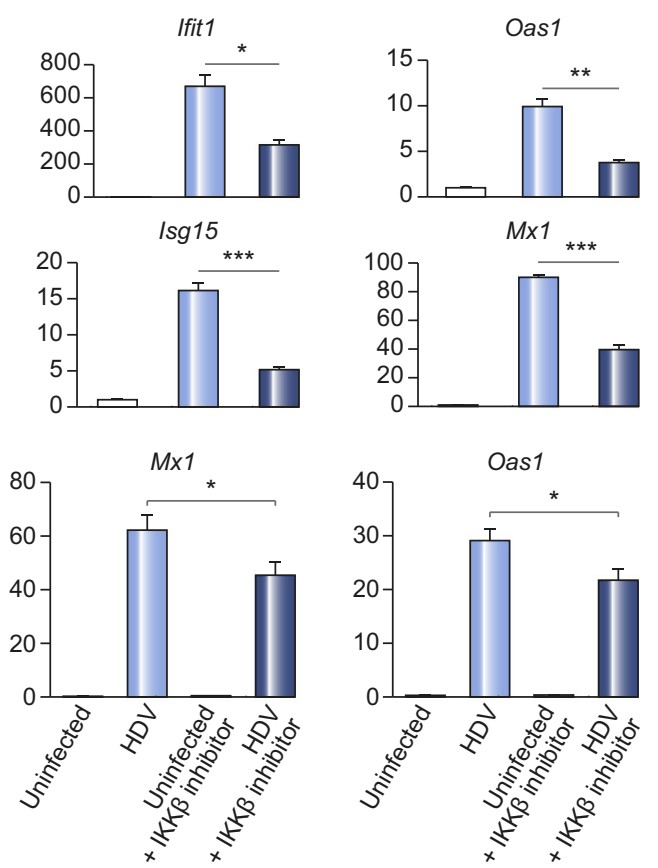
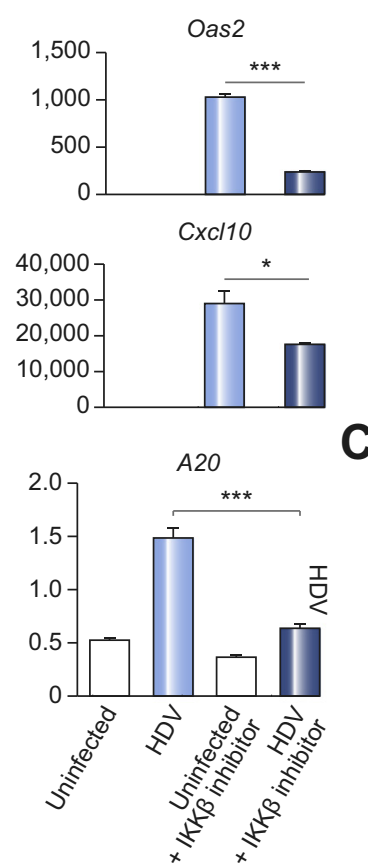

C
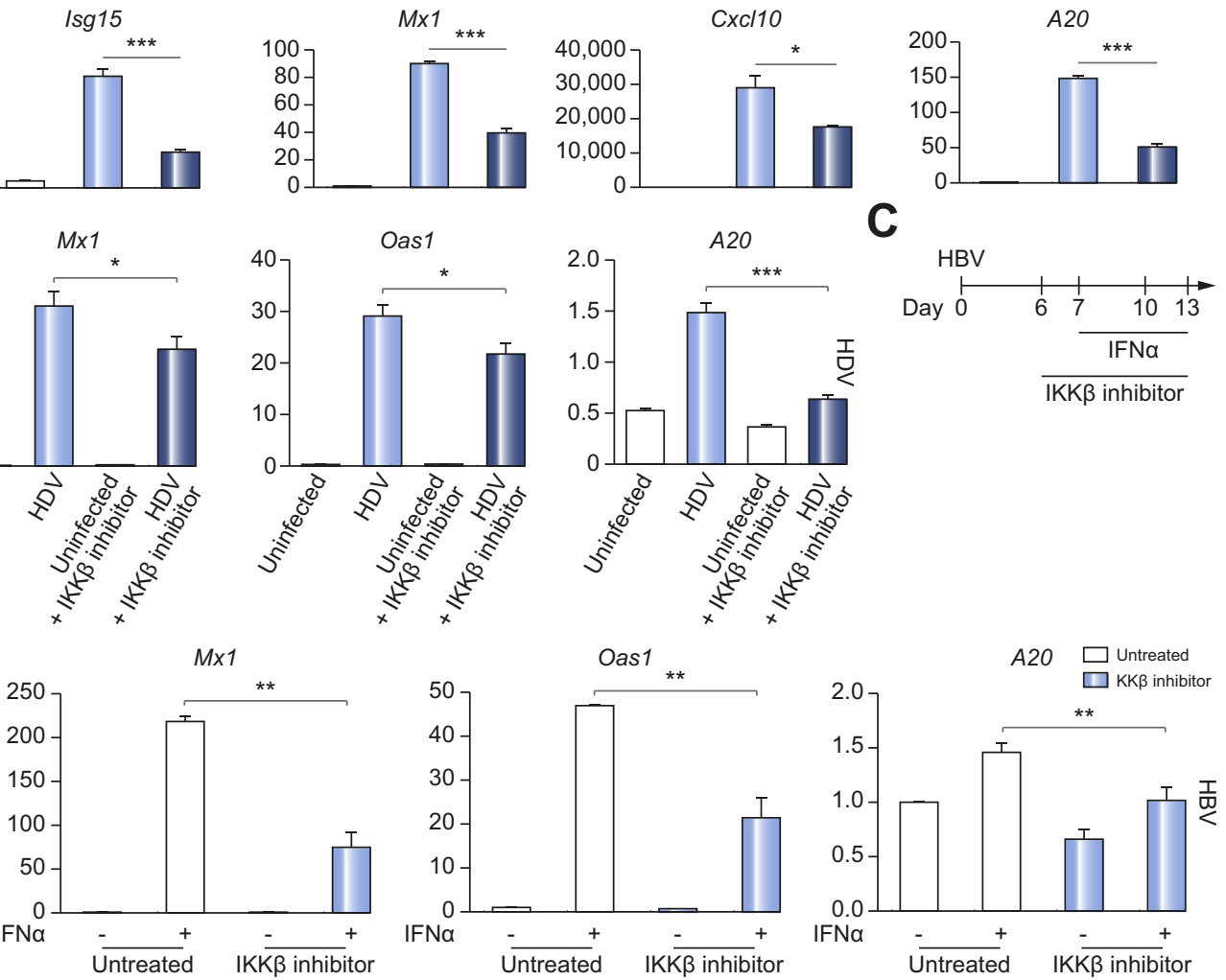

Fig. 6. HepaRG cells devoid of canonical NF-кB signaling exhibit reduced expression of ISGs. (A) HepaRGs lacking IKK $\beta$ (HepaRG-TR-Cas9 IKK $\beta$ ) and control HepaRGs (HepaRG-TR-Cas9 CTRL) were treated for $2 \mathrm{~h}$ with a combination of IFN- $\alpha(50 \mathrm{U} / \mathrm{ml})$ and TNF- $\alpha(10 \mathrm{ng} / \mathrm{ml})$. Expression profile of indicated ISGs measured by qRT-PCR. (B) dHepaRG were treated or not for $12 \mathrm{~h}$ with IKK2 Inhibitor (ML120B; $10 \mathrm{nM}$ ) and further infected with HDV and lysed 6 days later. qRT-PCR was performed with specific primers as indicated and normalized to the housekeeping gene, PRNP. (C) Schematic drawing of the performed experiment in Fig. D. HepaRGs were infected with HBV. After 6 days, cells were treated with TPCA1 $(10 \mathrm{nM})$. After 1 day of treatment, IFN- $\alpha$ (50 U/ml) was added to the medium up until day 13 p.i. (D) Total DNA and total RNA were extracted from dHepaRG. qRT-PCR was performed to verify the expression of ISGs. Error bars indicate mean \pm SEM, ${ }^{*} p \leq 0.05,{ }^{* *} p \leq 0.01,{ }^{* * *} p \leq 0.001$; unpaired Student's $t$ test. ISGs, interferon-stimulated genes; LCMV, lymphocytic choriomeningitis virus; NP, nuclear protein; qRT-PCR, quantitative reverse transcription PCR; WT, wild-type.

LCMV infection in mouse livers. LCMV infection has been used as a surrogate model for hepatitis virus infection. ${ }^{40}$ To determine whether similar mechanisms operated in human cells infected with distinct viruses, we utilized differentiated HepaRG cells (dHepaRG) devoid of IKK $\beta$ protein expression (HepaRG TR-Cas9 IKK $\beta$ ) generated by CRISPR/Cas9 gene editing or WT HepaRG cells (Figs. S5 A and B). The requirement for IKK $\beta$ in ISG induction was tested by treating with IFN- $\alpha$ alone or IFN- $\alpha /$ TNF $\alpha$. Similar to primary murine hepatocytes lacking IKK $\beta$ (Fig. 3 B), dHepaRG-TR-Cas9 IKK $\beta$ displayed significantly reduced ISG expression compared to Cas9-control dHepaRGs after exposure to IFN- $\alpha$ (data not shown) or IFN- $\alpha /$ TNF $\alpha$ (Fig. 6A).

HDV, a satellite virus of HBV, has been shown to strongly activate the IFN pathway in hepatocytes. ${ }^{41,42,43}$ We thus analyzed ISG mRNA expression upon HDV infection in the absence of NF-kB signaling in WT HepaRG and HepaRG-TR-Cas9 IKK $\beta$. To this end, a pharmacological inhibitor of NF- $\mathrm{KB}$ signaling (ML120B) was used to treat dHepaRG cells before infection with HDV. The levels of HDV-induced ISGs, such as Viperin, Mx1,
OAS1, were decreased in HepaRGs treated with inhibitor (Fig. 6B). Expression of the canonical NF-kB target gene A20, which induces a negative feedback loop to block NF- $\mathrm{kB}$ signaling, was slightly induced by HDV and blocked in the presence of the inhibitor (Fig. 6B). Consistent with these findings, HepaRGTR-Cas9 IKK $\beta$ cells infected with HDV displayed reduced expression of ISGs (Fig. S5C). Thus, NF-kB signaling appears to effectively increase the IFN response initiated by HDV in human dHepaRG.

Current knowledge from both experimental and clinical studies suggests that $\mathrm{HBV}$ is a weak inducer of innate responses (e.g. IFN and ISGs) and has evolved strategies to evade sensing. ${ }^{44,45,46}$ Thus, replication of HBV can be controlled by adding exogenous IFN- $\alpha$. We therefore tested whether the inhibitory action of IFN- $\alpha$ on HBV would be dampened in the absence of NF-KB signaling. To this end, a pharmacological inhibitor of NF- $\mathrm{KB}$ signaling was used to treat HBV-infected dHepaRGs. First, dHepaRGs were treated with IKK $\beta$ Inhibitor or control (DMSO) followed by IFN- $\alpha$ treatment alone. It has been 
shown that type I IFN signaling activates NF- $\kappa B$ signaling in various human and murine cell types. ${ }^{47}$ Consistently, IFN- $\alpha$ induced RelA phosphorylation was reduced in the presence of the NF- $\mathrm{KB}$ inhibitor, as verified by western blot analysis of protein lysates from inhibitor or mock-treated HepaRGs (Fig. S5 D). Next, IKK $\beta$ inhibitor or untreated dHepaRGs were infected with HBV and then treated with IFN- $\alpha$ (Fig. $6 \mathrm{C}$ ). IKK $\beta$ inhibition effectively dampened IFN- $\alpha$-mediated suppression of HBV DNA, RNA, as well as HBV antigens (HBsAg, $\mathrm{HBeAg}$ ) (Fig. S5E). Expression of ISGs such as Mx1, OAS1, and ISG15, required for controlling HBV replication, were decreased in HBV + IFN- $\alpha-$ treated HepaRGs in the presence of the IKK $\beta$ inhibitor (Fig. 6D). Moreover, expression of the canonical NF- $\kappa B$ target gene, A20, was also reduced (Fig. 6D). Thus, intact NF-kB signaling appears to be required for optimal effectiveness of IFN- $\alpha$ treatment against HBV infection.

To further decipher the role of NF- $\kappa B$ in the response to viral infection in patients, we analyzed the polymorphism of NF- $\kappa B 1$ in the serum of patients chronically infected with HCV or of patients who have resolved HCV infection (Fig. S6). To decipher the role of NF- $\kappa B$ in $\mathrm{HCV}$ infection, we analyzed 6 specific NF- $\kappa \mathrm{B} 1$ single nucleotide polymorphisms (SNPs) - including the homozygote $\left(\mathrm{SNP}^{+/+}\right)$, heterozygote $\left(\mathrm{SNP}^{+/}\right)$SNP state as well as the loss of SNP (SNPWT/WT $)$ in a cohort of approximately 80 patients. Three different groups of NF-кB1 SNPs were identified (Fig. S6): i) SNPs that are not significantly differentially represented between chronic HCV carriers and resolvers (SNP4 and SNP5); ii) Homozygote SNPs $(\mathrm{SNP}+/+)(\mathrm{SNP} 1$ and SNP2) that are significantly increased in chronic HCV carriers vs. HCV resolvers; iii) $\mathrm{SNP}^{\mathrm{WT}} / \mathrm{WT}$ (SNP3 and SNP6) which are significantly increased in chronic HCV carriers vs. HCV resolvers. Altogether, these results indicate that SNPS in NF- $\kappa B$ are correlated with clearance or chronic infection of HCV and thus may play a role in the resolution of HCV infection.

\section{Discussion}

While hepatocytes are known to execute metabolic functions in the liver, their role in antibacterial innate immunity has been well established, including expression of antibacterial proteins like complement proteins, opsonins and fibrinogen., ${ }^{7,48}$ Hepatic viral infections, such as HBV and HCV, lead to chronic hepatitis, cirrhosis and hepatocellular carcinoma, causing millions of deaths worldwide. ${ }^{3}$ During such chronic viral infections, innate sensing mechanisms are antagonized by viral proteins within infected hepatocytes which would otherwise control the virus, which implicates functional antiviral mechanisms within the cells. Work focused on delineating the involvement of liver cell types in clearing viral infections identified KCs as the principle cell type for viral control through IFN-mediated antiviral signaling. ${ }^{3}$ Considering that the major molecular signaling pathways involved in viral control within hepatocytes are similar to those in immune cells, we hypothesized that hepatocytederived innate immune signaling might play a central role in controlling hepatic viral infections.

Here, we show that hepatocyte-specific NF- $\mathrm{B}$ activation is essential for timely and efficient hepatic viral control. Loss of NF- $\kappa B$ signaling in hepatocytes resulted in a delay of the early IFN response and, consequently, in a 100 -fold virus titer increase in an LCMV-WE infection model. Of particular note, this blockade of NF$\kappa \mathrm{B}$ signaling in hepatocytes was sufficient to enhance virus replication despite the presence of intact overall hepatic IFN- $\alpha$ signaling in hepatocytes and fully functional KCs. The absence of LCMV in KCs from WT livers and its presence in KCs from $I k k \beta^{\Delta \text { Hep }}$ livers at day 8 p.i. - at a time point at which a robust adaptive immune response is activated - suggests that $\mathrm{KC}$-derived signaling alone (IFN, NF- $\kappa \mathrm{B}$ ) does not suffice to suppress viral growth in the liver when NF- $\kappa B$ signaling is inhibited in hepatocytes.

Initially, we considered the possibility that Kupfer cell- or other APC-derived signals might be required for LCMV-induced nuclear RelA translocation in hepatocytes, since KCs are known to be major producers of molecules that stimulate NF-kB signaling, including TNF $\alpha$. However, nuclear RelA translocation in hepatocytes after LCMV-WE infection persisted even when KCs were depleted or when TNFR1 was knocked out. This indicated that nuclear RelA translocation was independent of molecular cues/cytokines derived from KCs/APCs, the TNFTNFR1-axis and could be a result of direct sensing of LCMV by PRRs within the hepatocytes, as highlighted by the decrease of RelA translocation upon TLR3, TLR7, MyD88, or MAVS knockdown. For control, Sting ${ }^{-/-}$mice did not display a decrease in RelA translocation.

Mice with hepatocyte-specific deletion of $\operatorname{IKK} \beta\left(\operatorname{Ikk} \beta^{\Delta \mathrm{Hep}}\right)$ and consequently defective RelA translocation showed increased virus replication and delayed virus clearance. Thus, induction of RelA in hepatocytes contributes to efficient virus control in the liver. Notably, in livers of $I k k \beta^{\Delta H e p}$ mice, IFN-induced mRNA expression of ISGs and consequent phosphorylation of STAT1 was found to be delayed and reduced in the hepatocytic compartment, whereas it was still immunopositive in the nonparenchymal cell compartment compared to the livers of WT mice in which both hepatocytes and non-parenchymal cells exhibited equal levels of pSTAT1. Interestingly, this happened in the context of unchanged IFN- $\alpha /$ IFN- $\beta$ expression levels in $I k k \beta^{\Delta \mathrm{Hep}}$ mice. We next found that livers depleted of KCs by clodronate also expressed IFN- $\beta$ levels similar to WT, whereas some ISGs were expressed at lower levels in clodronate-treated livers. The residual IFN- $\beta$ expression in KC-depleted livers could plausibly be derived from other immune cells. Our experiments indicated that myeloid cells expressing IFNAR are important for inducing the early expression of ISGs and hepatocytic pSTAT1. Interestingly, reduced IFN- $\beta$ expression and a delay in pSTAT1 translocation in hepatocytes in Ifnar ${ }^{\Delta \text { Myel }}$ livers indicate that hepatocytes might require initial IFN cues from KCs. Accordingly, during the effector phase of infection at day 6 p.i., there was a massive accumulation of LCMV in both KCs and hepatocytes in Ifnar ${ }^{\Delta \text { Myel }}$ livers. Remarkably, by day 8 p.i. there was a strong decrease in the number of infected hepatocytes, whereas LCMV levels in myeloid cells remained high. This indicated that hepatocyte-specific ISG expression and viral control within hepatocytes, eventually occurred despite the lack of IFN signaling or viral control in KCs - either due to autocrine antiviral signaling within hepatocytes and/or paracrine signals from other cells (e.g. plasmacytoid dendritic cells).

In addition, our work underlines that the hepatic increase of LCMV found in Ikk $\beta^{\Delta \mathrm{Hep}}$ mice is independent of LCMV-induced splenic responses, as similar levels of splenic $\mathrm{CD} 169^{+}$macrophages and splenic dendritic cell maturation were found in WT and $I k k \beta^{\Delta \mathrm{Hep}}$ mice. This finding highlights that the increased viral replication in $I k k \beta^{\Delta H e p}$ livers is a causal effect of a diminished hepatocyte-intrinsic innate immune response.

It is well established that canonical NF- $\kappa B$ subunits ( $p 50: p 65)$ are part of an enhanceosome complex along with ATF-2/c-Jun, 


\section{JOURNAL OF HEPATOLOGY}

IRF-3/IRF-7 that activates IFN- $\beta$ gene expression. Also, it is known that NF- $\mathrm{KB}$ activation is required for the induction of proinflammatory cytokines, as well as early expression of IFN- $\beta$ during RNA virus infection and to maintain a basal level of IFN and interferon-inducible genes. ${ }^{49-52}$ Since NF-kB and antiviral signaling mechanisms exist in hepatocytes which constitute approximately $80 \%$ of the entire liver mass, we hypothesized that defective NF-KB within hepatocytes would blunt the overall antiviral response in the liver. Consistent with this hypothesis, we could successfully demonstrate a direct link between the requirement of hepatocyte-intrinsic NF- $\mathrm{KB}$ signaling and IFN- $\alpha$ responses by treating hepatocytes lacking IKK $\beta$ with IFN- $\alpha$ directly in vitro and in vivo. In both cases, ISG expression was decreased significantly in the absence of IKK $\beta$. We could also corroborate these observations in HDV infection models or with IFN- $\alpha+$ TNF $\alpha$ treatment of dHepaRGs, where we saw blunted expression of ISGs in dHepaRGs lacking NF-kB signaling. ${ }^{50,51}$

Consistent with our data, mice with hepatocyte-specific deletion of Ifnar displayed strongly reduced ISG expression and strongly increased LCMV in hepatocytes as early as 6 days p.i. Thus, the presence of both IFNAR and NF-KB signaling in hepatocytes is needed to execute optimal and timely ISG responses and control hepatic viral LCMV infection - with IKK $\beta$ and NF-kB signaling serving as amplifiers of IFNAR signaling. Moreover, these data point to hepatocytes being an important producer of ISGs through IFNAR signaling.

Of note, expression of IFN-induced chemokines such as CXCL9, CXCL10 and CXCL11, important for the attraction of monocytes and other immune cells, ${ }^{53-55}$ were also reduced in the livers of $I k k \beta^{\Delta}$ Hep mice compared to WT. This decrease was accompanied by a reduction in the number of effector $\mathrm{CD} 8^{+} T$ cells in Ikk $\beta^{\Delta \text { Hep }}$ livers at early time points (day 6 and 8 p.i.) following LCMV infection. Notably, once LCMV infection has been controlled in both models at late time points (later than/around 15 days p.i.), no differences in hepatic $\mathrm{CD}^{+} \mathrm{T}$ cell numbers could be detected. We also saw a reduction in the intrahepatic influx of innate immune cells in $I k k \beta^{\Delta \mathrm{Hep}}$ mice. Thus, in addition to impaired hepatocyte-intrinsic viral control, loss of NF-kB signaling in hepatocytes also prevents the liver from mounting an optimal innate and adaptive immune response, which may further promote viral accumulation and may at least partially account for the observed increase in the number of LCMV-positive KCs identified in $I k k \beta^{\Delta \mathrm{Hep}}$ livers in the current study ${ }^{56,57}$ However, at later time points (between days 8 and 20 p.i.) LCMV-WE infection was controlled - even in the absence of NF- $\mathrm{KB}$ signaling in hepatocytes.

LCMV-WE can infect and replicate in both KCs and hepatocytes, triggering potent innate and adaptive immune responses. In the case of KC infection - innate immune responses can support viral elimination, although with a delay - even in the absence of hepatocytic NF- $\mathrm{kB}$. However, other hepatic viruses which specifically target hepatocytes, such as HBV or HDV, might not trigger immune responses in KCs in the absence of NF- $\mathrm{KB}$ signaling in hepatocytes, preventing the elimination of the infection.

Recently, a correlation was indeed demonstrated between NF-KB SNPs and susceptibility to HCV infection in different Chinese populations, highlighting a role of NF- $\mathrm{KB}$ in the control of hepatic viral infection. ${ }^{58,59}$

We analyzed the expression of 6 SNPs of NF-kB1 in the serum of approximately 80 patients with chronic or resolved $\mathrm{HCV}$ infection. These results confirmed the previously published data, ${ }^{58,59}$ emphasizing a possible role of NF- $\mathrm{KB}$ in the activation of innate immune responses (such as IFN production and signaling) and in the control/resolution of hepatic viral infection.

Moreover, we showed that NF-kB signaling is required for viral control in hepatocytes in human cells (dHepaRG) and for another virus (HDV). HBV usually does not induce strong IFN responses. ${ }^{60}$ Thus, administration of IFN- $\alpha$ is a common therapeutic strategy for the treatment of this disease. In the current study, we demonstrated that NF-kB signaling is required for the therapeutic effects of IFN- $\alpha$ treatment in the context of an HBV infection. Thus, NF-kB signaling in hepatocytes may play a broad role in the pathogenesis of viral liver infections, as well as the molecular mechanisms underlying the efficacy of some antiviral therapies.

In summary, we conclude that infected hepatocytes in the liver actively sense viral replication and initiate/incorporate autocrine and paracrine IFN signaling cascades and contribute to the overall production of cytokines, chemokines and ISGs. When $\mathrm{NF}-\mathrm{KB}$ signaling is impaired in hepatocytes, ISGs responses in the liver becomes markedly delayed and reduced, virus accumulates within hepatocytes, and the usually well-orchestrated adaptive immune responses during the effector phase of the infection are less effective and delayed. Thus, we propose a model of hepatic LCMV infection that can be divided in distinct phases: In the first "wave", LCMV infects macrophages, which is associated with a strong innate immune response in these cells (e.g. TNF $\alpha$ ). This first wave primes the upcoming wave through the secretion of IFNs, inducing the first ISGs within the liver (e.g. in KCs and other innate immune cells). In the second "wave", LCMV is sensed by hepatocytes, preventing the establishment of the virus in cells with functional NF- $\mathrm{kB}$ signaling and potent PRR responses. Taken together, our results highlight the role played by hepatocytederived NF- $\mathrm{kB}$ in supporting IFN-mediated immune responses and early resistance to hepatic viral infections.

\section{Abbreviations}

APCs, antigen-presenting cells; IFN, interferon; IFNRA, type I interferon receptors; ISG, interferon-stimulated gene; KCs, Kupffer cells; LCMV, lymphocytic choriomeningitis virus; NP, nuclear protein; PAMPs, pathogen-associated molecular patterns; PFUs, plaque-forming units; PRR, pathogen recognition receptors; qRT-PCR, quantitative reverse transcription PCR; SNPs, single nucleotide polymorphisms; TLR, Toll-like receptor; WT, wild-type.

\section{Financial support}

This manuscript was supported by the SFBTR179 and 209 to M.H., U.P., P.K. and M.B. M.H. was supported by an ERC consolidator grant (HeaptoMetaboPath), the EOS grant (Flundern) and a Horizon 2020 grant. I.S. was supported by an Emmy Noether Program.

\section{Conflict of interest}

The following authors declare no competing financial interests: S.N., T.O., S.F.D, P.J., T.R., K.L., H.X., I.S., P.S., F.L., A.P., P.Sh., M.R., A.M., K.B., P.B., S.L., D.D., R.F., A.W., D.L., T.K., P.St., U.P, D.W., B.H., M.B., K.B., L.M.A., J.N., Z.A., M.R., E.D., P.L., K.L., M.K., J.L., U.K., P.K., M.H.

Please refer to the accompanying ICMJE disclosure forms for further details.

\section{Authors' contributions}

M.H., S.N. and T.O. conceived the study. S.N., T.O., S.F.D. and M.H. designed all the experiments. S.N., T.O., S.F.D., P.J., T.R., K.L., H.X., 
I.S., P.S., F.L., A.P., P.Sh., M.R., A.M., K.B., P.B., S.K., R.F., D.L., P.St., D.W., Z.A., M.R., J.L., L.M.A. performed experiments. S.N., T.O., S.F.D., and M.H. wrote the manuscript. T.O. co-supervised the study. P.K. gave critical inputs to the study, provided reagents and performed experiments together with D.W., S.K., J.N. and Z.A., D.D., A.W., T.K., U.P., B.H., M.B., K.Br., E.D., P.L., K.L., M.K., U.K. and all authors contributed to the development of the manuscript.

\section{Acknowledgments}

We thank Ruth Hillermann, Danijela Heide, Olga Seelbach, Sandra Prokosch, Rebecca Balduf and Jenny Hetzer for their excellent technical support. We thank the Tissue Bank of the National Center for Tumor Diseases (NCT) Heidelberg, Germany and the Institute of Pathology, Heidelberg University Hospital, Germany, for they support in scanning the stained slides.

\section{Supplementary data}

Supplementary data to this article can be found online at https:// doi.org/10.1016/j.jhep.2019.12.019.

\section{References}

\section{Author names in bold designate shared co-first authorship}

[1] Macpherson AJ, Heikenwalder M, Ganal-Vonarburg SC. The liver at the nexus of host-microbial interactions. Cell Host Microbe 2016;20:561-571.

[2] Huang LR, Wohlleber D, Reisinger F, Jenne CN, Cheng RL, Abdullah Z, et al. Intrahepatic myeloid-cell aggregates enable local proliferation of CD8(+) T cells and successful immunotherapy against chronic viral liver infection. Nat Immunol 2013;14:574-583.

[3] Ringelhan M, Pfister D, O'Connor T, Pikarsky E, Heikenwalder M. The immunology of hepatocellular carcinoma. Nat Immunol 2018;19:222232.

[4] Ebe Y, Hasegawa G, Takatsuka H, Umezu H, Mitsuyama M, Arakawa M, et al. The role of KCs and regulation of neutrophil migration into the liver by macrophage inflammatory protein-2 in primary listeriosis in mice. Pathol Int 1999;49:519-532.

[5] Lee WY, Moriarty TJ, Wong CH, Zhou H, Strieter RM, van Rooijen N, et al. An intravascular immune response to Borrelia burgdorferi involves KCs and iNKT cells. Nat Immunol 2010;11:295-302.

[6] Crispe IN. Hepatocytes as immunological agents. J Immunol 2016;196: $17-21$.

[7] Zhou Z, Xu MJ, Gao B. Hepatocytes: a key cell type for innate immunity. Cell Mol Immunol 2016;13:301-315.

[8] Faure-Dupuy S, Vegna S, Aillot L, Dimier L, Esser K, Broxtermann M, et al. Characterization of pattern recognition receptor expression and functionality in liver primary cells and derived cell lines. J Innate Immun 2018;10:1-10.

[9] Zhang X, Meng Z, Qiu S, Xu Y, Yang D, Schlaak JF, et al. Lipopolysaccharideinduced innate immune responses in primary hepatocytes downregulates woodchuck hepatitis virus replication via interferon-independent pathways. Cell Microbiol 2009;11:1624-1637.

[10] Schneider WM, Chevillotte MD, Rice CM. Interferon-stimulated genes: a complex web of host defenses. Annu Rev Immunol 2014;32:513-545.

[11] Lee KJ, Novella IS, Teng MN, Oldstone MB, de La Torre JC. NP and L proteins of lymphocytic choriomeningitis virus (LCMV) are sufficient for efficient transcription and replication of LCMV genomic RNA analogs. J Virol 2000;74:3470-3477.

[12] Buchmeier MJ, Welsh RM, Dutko FJ, Oldstone MB. The virology and immunobiology of lymphocytic choriomeningitis virus infection. Adv Immunol 1980;30:275-331.

[13] Pichlmair A, Schulz O, Tan CP, Naslund TI, Liljestrom P, Weber F, et al. RIGI-mediated antiviral responses to single-stranded RNA bearing 5'-phosphates. Science 2006;314:997-1001.

[14] Marq JB, Hausmann S, Veillard N, Kolakofsky D, Garcin D. Short doublestranded RNAs with an overhanging 5' ppp-nucleotide, as found in arenavirus genomes, act as RIG-I decoys. J Biol Chem 2011;286:6108-6116.

[15] Karin M, Ben-Neriah Y. Phosphorylation meets ubiquitination: the control of NF-[kappa]B activity. Annu Rev Immunol 2000;18:621-663.
[16] Pasparakis M. Regulation of tissue homeostasis by NF-kappaB signalling: implications for inflammatory diseases. Nat Rev Immunol 2009;9:778788.

[17] Hiscott J, Kwon H, Genin P. Hostile takeovers: viral appropriation of the NF-kappaB pathway. J Clin Invest 2001;107:143-151.

[18] Mohamed MR, McFadden G. NFkB inhibitors: strategies from poxviruses Cell Cycle 2009;8:3125-3132.

[19] Chu WM, Ostertag D, Li ZW, Chang L, Chen Y, Hu Y, et al. JNK2 and IKKbeta are required for activating the innate response to viral infection. Immunity 1999;11:721-731.

[20] Postic C, Shiota M, Niswender KD, Jetton TL, Chen Y, Moates JM, et al. Dual roles for glucokinase in glucose homeostasis as determined by liver and pancreatic beta cell-specific gene knock-outs using Cre recombinase. J Biol Chem 1999;274:305-315.

[21] Maeda S, Chang L, Li ZW, Luo JL, Leffert H, Karin M. IKKbeta is required for prevention of apoptosis mediated by cell-bound but not by circulating TNFalpha. Immunity 2003;19:725-737.

[22] Park JM, Greten FR, Li ZW, Karin M. Macrophage apoptosis by anthrax lethal factor through p38 MAP kinase inhibition. Science 2002;297:20482051.

[23] Maeda S, Kamata H, Luo JL, Leffert H, Karin M. IKKbeta couples hepatocyte death to cytokine-driven compensatory proliferation that promotes chemical hepatocarcinogenesis. Cell 2005;121:977-990.

[24] Lang PA, Recher M, Honke N, Scheu S, Borkens S, Gailus N, et al. Tissue macrophages suppress viral replication and prevent severe immunopathology in an interferon-I-dependent manner in mice. Hepatology 2010;52:25-32.

[25] Lukashevich IS, Rodas JD, Tikhonov II, Zapata JC, Yang Y, Djavani M, et al. LCMV-mediated hepatitis in rhesus macaques: WE but not ARM strain activates hepatocytes and induces liver regeneration. Arch Virol 2004;149:2319-2336.

[26] Kamphuis E, Junt T, Waibler Z, Forster R, Kalinke U. Type I interferons directly regulate lymphocyte recirculation and cause transient blood lymphopenia. Blood 2006;108:3253-3261.

[27] Labun K, Montague TG, Gagnon JA, Thyme SB, Valen E. CHOPCHOP v2: a web tool for the next generation of CRISPR genome engineering. Nucleic Acids Res 2016;44:W272-W276.

[28] Cao J, Wu L, Zhang SM, Lu M, Cheung WK, Cai W, et al. An easy and efficient inducible CRISPR/Cas9 platform with improved specificity for multiple gene targeting. Nucleic Acids Res 2016;44:e149.

[29] Wiese M, FB, Lafrenz M, Porst H, Oesen U. Low frequency of cirrhosis in a hepatitis C (genotype 1b) single-source outbreak in Germany: a 20-year multicenter study. Hepatology 2000;32:91-96.

[30] Pinschewer DD, Perez M, de la Torre JC. Role of the virus nucleoprotein in the regulation of lymphocytic choriomeningitis virus transcription and RNA replication. J Virol 2003;77:3882-3887.

[31] Bose S, Kar N, Maitra R, DiDonato JA, Banerjee AK. Temporal activation of NF-kappaB regulates an interferon-independent innate antiviral response against cytoplasmic RNA viruses. Proc Natl Acad Sci U S A 2003;100:10890-10895.

[32] Pauls E, Shpiro N, Peggie M, Young ER, Sorcek RJ, Tan L, et al. Essential role for IKKbeta in production of type 1 interferons by plasmacytoid dendritic cells. J Biol Chem 2012;287:19216-19228.

[33] Sadler AJ, Williams BR. Interferon-inducible antiviral effectors. Nat Rev Immunol 2008:8:559-568.

[34] Clausen BE, Burkhardt C, Reith W, Renkawitz R, Forster I. Conditional gene targeting in macrophages and granulocytes using LysMcre mice. Transgenic Res 1999;8:265-277.

[35] Garcia-Sastre A, Biron CA. Type 1 interferons and the virus-host relationship: a lesson in detente. Science 2006;312:879-882.

[36] Srivastava S, Koch MA, Pepper M, Campbell DJ. Type I interferons directly inhibit regulatory T cells to allow optimal antiviral T cell responses during acute LCMV infection. J Exp Med 2014;211:961-974.

[37] Groom JR, Luster AD. CXCR3 in T cell function. Exp Cell Res 2011;317: 620-631.

[38] Harvey CE, Post JJ, Palladinetti P, Freeman AJ, Ffrench RA, Kumar RK, et al. Expression of the chemokine IP-10 (CXCL10) by hepatocytes in chronic hepatitis $C$ virus infection correlates with histological severity and lobular inflammation. J Leukoc Biol 2003;74:360-369.

[39] Nishioji K, Okanoue T, Itoh Y, Narumi S, Sakamoto M, Nakamura H, et al. Increase of chemokine interferon-inducible protein-10 (IP-10) in the serum of patients with autoimmune liver diseases and increase of its mRNA expression in hepatocytes. Clin Exp Immunol 2001;123:271279. 
[40] Lang PA, Contaldo C, Georgiev P, El-Badry AM, Recher M, Kurrer M, et al. Aggravation of viral hepatitis by platelet-derived serotonin. Nat Med 2008;14:756-761.

[41] Alfaiate D, Lucifora J, Abeywickrama-Samarakoon N, Michelet M, Testoni B, Cortay JC, et al. HDV RNA replication is associated with HBV repression and interferon-stimulated genes induction in super-infected hepatocytes. Antivir Res 2016;136:19-31.

[42] Williams V, Brichler S, Radjef N, Lebon P, Goffard A, Hober D, et al. Hepatitis delta virus proteins repress hepatitis B virus enhancers and activate the alpha/beta interferon-inducible MxA gene. J Gen Virol 2009;90:2759-2767.

[43] Giersch K, Helbig M, Volz T, Allweiss L, Mancke LV, Lohse AW, et al. Persistent hepatitis D virus mono-infection in humanized mice is efficiently converted by hepatitis B virus to a productive co-infection. J Hepatol 2014;60:538-544.

[44] Luangsay S, Gruffaz M, Isorce N, Testoni B, Michelet M, Faure-Dupuy S, et al. Early inhibition of hepatocyte innate responses by hepatitis B virus. J Hepatol 2015;63:1314-1322.

[45] Wieland S, Thimme R, Purcell RH, Chisari FV. Genomic analysis of the host response to hepatitis B virus infection. Proc Natl Acad Sci U S A 2004;101:6669-6674.

[46] Dunn C, Peppa D, Khanna P, Nebbia G, Jones M, Brendish N, et al. Temporal analysis of early immune responses in patients with acute hepatitis B virus infection. Gastroenterology 2009;137:1289-1300.

[47] Yang CH, Murti A, Pfeffer SR, Basu L, Kim JG, Pfeffer LM. IFNalpha/beta promotes cell survival by activating NF-kappa B. Proc Natl Acad Sci U S A 2000;97:13631-13636.

[48] Volanakis JE. Transcriptional regulation of complement genes. Annu Rev Immunol 1995;13:277-305.

[49] Panne D, Maniatis T, Harrison SC. An atomic model of the interferon-beta enhanceosome. Cell 2007;129:1111-1123.

[50] Wang J, Basagoudanavar SH, Wang X, Hopewell E, Albrecht R, GarciaSastre A, et al. NF-kappa B RelA subunit is crucial for early IFN-beta expression and resistance to RNA virus replication. J Immunol 2010;185:1720-1729.
[51] Basagoudanavar SH, Thapa RJ, Nogusa S, Wang J, Beg AA, Balachandran S. Distinct roles for the NF-kappa B RelA subunit during antiviral innate immune responses. J Virol 2011;85:2599-2610.

[52] Rubio D, Xu RH, Remakus S, Krouse TE, Truckenmiller ME, Thapa RJ, et al. Crosstalk between the type 1 interferon and nuclear factor kappa B pathways confers resistance to a lethal virus infection. Cell Host Microbe 2013;13:701-710.

[53] Dufour JH, Dziejman M, Liu MT, Leung JH, Lane TE, Luster AD. IFN-gammainducible protein 10 (IP-10; CXCL10)-deficient mice reveal a role for IP-10 in effector T cell generation and trafficking. J Immunol 2002;168:31953204.

[54] Khan IA, MacLean JA, Lee FS, Casciotti L, DeHaan E, Schwartzman JD, et al. IP-10 is critical for effector T cell trafficking and host survival in Toxoplasma gondii infection. Immunity 2000;12:483-494.

[55] Liu MT, Chen BP, Oertel P, Buchmeier MJ, Armstrong D, Hamilton TA, et al. The T cell chemoattractant IFN-inducible protein 10 is essential in host defense against viral-induced neurologic disease. J Immunol 2000;165: 2327-2330.

[56] Wilson EB, Yamada DH, Elsaesser H, Herskovitz J, Deng J, Cheng G, et al. Blockade of chronic type I interferon signaling to control persistent LCMV infection. Science 2013;340:202-207.

[57] Teijaro JR, Ng C, Lee AM, Sullivan BM, Sheehan KC, Welch M, et al. Persistent LCMV infection is controlled by blockade of type I interferon signaling. Science 2013;340:207-211.

[58] Fan HZ, Huang P, Shao JG, Tian T, Li J, Zang F, et al. Genetic variation on the NFKB1 genes associates with the outcomes of HCV infection among Chinese Han population. Infect Genet Evol 2018;65:210-215.

[59] Tian T, Wang J, Huang P, Li J, Yu R, Fan H, et al. Genetic variations in NF-кB were associated with the susceptibility to hepatitis $C$ virus infection among Chinese high-risk population. Sci Rep 2018;8(1):104.

[60] Mutz P, Metz P, Lempp FA, Bender S, Qu B, Schoneweis K, et al. HBV bypasses the innate immune response and does not protect HCV from antiviral activity of interferon. Gastroenterology 2018;154(6):17911804.e2. 